\title{
LA REVOLUCION INDUSTRIAL Y LA NUEVA HISTORIA ECONOMICA (I) *
}

\author{
JOEL MOKYR ${ }^{1}$ \\ Northwestern University
}

Ha transcurrido casi un siglo desde la publicación de la famosa obra de Arnold Toynbee, Lectures on the Industrial Revolution (1884) ${ }^{2}$. Desde entonces, historiadores de todas las escuelas han llegado a la conclusión de que la Revolución Industrial en Gran Bretaña constituyó un nuevo punto de partida en la historia de la humanidad, un hecho de tanta importancia para la vida cotidiana que puede compararse con la aparición del monoteísmo o con el desarrollo del lenguaje. De este modo, ha surgido una extensa literatura escrita por historiadores, economistas y sociólogos, ingleses y extranjeros, tanto de izquierdas como de derechas, que trata de sus diversos aspectos. Sin embargo, los expertos no se han puesto de acuerdo sobre los problemas fundamentales. En primer lugar se encuentra la mera cuestión de la definición: ¿qué fue exactamente la Revolución Industrial ${ }^{3}$ De los muchos intentos que se han efectuado para resumir lo que supuso la Revolución Industrial, el de Perkin es quizá el más elocuente. En sus propias palabras, fue «una revolución

* Versión revisada y ampliada de la introducción a Mokyr (1985).

'Muchos colegas hicieron comentarios a versiones anteriores del manuscrito, lo que originó importantes mejoras tanto de estilo como de contenido. Entre ellos se encuentran Louis Cain, Carolyn Crane, Stefano Fenoaltea, Jack Goldstone, Jonathan Hughes, Eric L. Jones, Peter Lindert, John Lyons, Joram Mayshar, Donald N. McCloskey, Jacob Metzer y Jeffrey Williamson.

2 Como es ahora bien conocido, el economista francés Jerome Adolphe Blanqui (17981854), en su obra Histoire de l'economie politique (1837, p. 389), fue el primero en utilizar el término «Revolución Industrial». Un año después, el periodista y publicista belga Natalis de Briavoinne (1838, vol. I, pp. 185 y ss.) empleó el término, probablemente de manera independiente. Un tercer hito en la utilización del término fue la traducción al inglés de la clásica obra de Paul Mantoux (1961; 1." ed. inglesa, 1928; 1." ed. francesa, 1905).

${ }^{3}$ En un artículo reciente, Fores (1981) ha examinado las diferencias que existen entre los estudiosos de este tema. Documenta las confusiones semánticas en la literatura y deduce de ellas que los conceptos «industrial» y «revolución» significan cosas distintas para autores diferentes. Aunque, indudablemente, esta conclusión es correcta, no es probable que encuentre mucho apoyo su sugerencia de dejar de utilizar el término por completo. En historia económica existen otros conceptos - piénsese en «capitalismo», "feudalismo" e «imperalismo»- que han sido utilizados de forma diversa por distintos autores, pero sería una locura abandonarlos por este motivo. 
en el acceso de los hombres a los medios de vida, en el control de su entorno ecológico, en su capacidad de escapar de la tiranía y de la mezquindad de la naturaleza (...) abrió el camino a los hombres para completar el dominio de su entorno físico, sin la ineludible necesidad de explotarse unos a otros» (Perkin, 1969, pp. 3-5). En Gran Bretaña cambiaron muchas cosas, y no solamente la manera en que se producían los bienes y servicios. Se transformó la naturaleza de la familia y del hogar, el status de las mujeres y los niños, el papel de la Iglesia, cómo las personas elegían a los gobernantes y mantenían a los pobres, lo que sabían acerca del mundo y lo que querían saber. El descubrimiento de cómo estas transformaciones no económicas afectaron y se vieron afectadas por el cambio económico es un proyecto continuo. La revolución fue, en frase irresistible de Perkin, «algo más que una Revolución Industrial». Al centrarnos en la economía aislamos sólo una parte, aunque fundamental, de la modernización de Gran Bretaña.

Se han planteado cuestiones difíciles y ambiciosas: ¿Cuáles fueron las causas de la Revolución Industrial? ¿Por qué se produjo cuando lo hizo? ¿Cuáles fueron los efectos en la economía y en el bienestar social de la población? ¿Qué papeles desempeñaron la agricultura, el crecimiento de la población, los elementos políticos, el transporte y el comercio exterior? A comienzos de los años sesenta todavía no se había llegado a ningún acuerdo ${ }^{4}$. Los que busquen respuestas definitivas no deben dirigirse a la historia económica. Sin embargo, la importancia intrínseca del tema ha mantenido interesados a eruditos y estudiosos, y la literatura que trata de la Revolución Industrial ha aumentado extensamente en la última década, dando lugar a animadas polémicas. Esta tendencia a generar debates no es un inconveniente; el enemigo mortal de la historia económica no es el error, sino el aburrimiento. En tanto que el tema sea capaz de producir enérgicas discusiones entre algunas de las mentes más brillantes que trabajan en los departamentos de economía y de historia, se le debe considerar vigente.

En las dos últimas décadas, los economistas han desempeñado un papel creciente en la historiografía de la Revolución Industrial. Una Nueva Historia Económica, deseosa de aplicar sus herramientas a nuevas materias, consideró la Revolución Industrial como un objetivo fácil. En efecto, algunos estudiosos han expresado la esperanza de que el análisis económico y los modelos cuantitativos resolverían algunas de las controversias (Hartwell, 1971, pp. 133. 134). No obstante, se debe señalar que la Nueva Historia Económica ha demostrado estar mejor capacitada para responder a las preguntas que ella mis-

4 El número de Past and Present de julio de 1961 recogió las actas de una conferencia celebrada para tratar de estos temas. R. M. Hartwell (1967, p. 5) resume lacónicamente el resultado como "poco sistemático y poco convincente y que no mejoró en nada la comprensión de las causas de la Revolución Industrial». 
ma se plantea, con frecuencia cuestiones bien definidas que producen hipótesis claras y refutables. De hecho, la misma precisión de los nuevos métodos les ha limitado a un grupo restringido de problemas.

Una valiosa aportación de los economistas ha sido la utilización más refinada e ingeniosa de las estadísticas con el fin de contrastar las hipótesis acerca de las relaciones causales en la Revolución Industrial ${ }^{5}$. La Nueva Historia Económica ha empleado las estadísticas existentes de forma nueva e imaginativa, y ha incrementado significativamente el conjunto de información cuantitativa referente a Inglaterra durante la Revolución Industrial ${ }^{6}$. Pero lo que es más importante, la Nueva Historia Económica ha impuesto ciertos criterios de lógica económica en este campo. Los economistas no tienen menos prejuicios o están menos influidos políticamente que otros científicos sociales, y, ciertamente, no monopolizan el sentido común (a pesar de las fuertes convicciones de algunos miembros de la profesión). Pero, al menos, la economía admite menos errores lógicos que otras ciencias sociales, y, cuando un economista los comete, él o ella pueden contar con que otros economistas se los indicarán sin compasión ${ }^{7}$. Aunque las discusiones continúan, se debate con instrumentos más aguzados y exactos que antes. Las argumentaciones pueden demostrarse - al menos en principio- equivocadas. Por ejemplo, se sigue sosteniendo a veces que el crecimiento de la población condujo al crecimiento económico (Boserup, 1981, p. 112), y que fue un importante factor causal de la Revolución Industrial en Gran Bretaña. El análisis económico puede dejar al descubierto los supuestos bajo los que se mantiene esta teoría. Lo que tiene que ocurrir es, o bien una relación directa entre el crecimiento de la población y el cambio tecnológico (un nexo difícil de documentar), o bien que las economías de escala sean lo bastante fuertes como para contrarrestar los efectos negativos de los rendimientos decrecientes. Estas condiciones se

5 Algunos de estos datos han estado disponibles durante muchas décadas (por ejemplo, los datos de salarios recogidos por Bowley en la década de 1890); otros se han creado más recientemente (Hoffmann, 1955; Gayer, Rostow y Schwartz, 1953; Davis, 1978). El trabajo que, sobre todo, ha suministrado a los cliómetras tanto munición como blanco para practicar sus técnicas ha sido la obra de DeAne y Cole British Economic Growth, 1688-1959 (1969). Entre los artículos que critican la interpretación de Deane y Cole, aunque se apoyan con libertad en sus datos, se encuentran Crafts (1976, 1983), Williams (1966) y Hatton, Lyons y Satchell (1983).

- Para artículos que utilizaron datos existentes, véanse en especial Blaug (1961), Harley (1982) y Von Tunzelmann (1978). Los artículos de Williamson y Lindert (1983) y Feinstein (1978) son ejemplos del nuevo material.

' Así, por ejemplo, un economista (Engerman, 1972) ha desenmascarado el mito de que los beneficios del tráfico de esclavos realizado por los británicos fueran un factor causal de la Revolución Industrial. Igualmente, O'Brien (1982) ha pulverizado la noción de que la Revolución Industrial que se dio en Gran Bretaña fue el resultado de la explotación parasitaria de la periferia no europea por el núcleo europeo. Véase también el intercambio entre Crafts $(1977,1978)$ y Rostow (1978). 
pueden contrastar, y si bien estos contrastes, por su misma naturaleza, no pueden ser absolutos, son la clave para distinguir entre lo posible y lo probable.

\section{Algunos problemas de definición}

Se ha dicho que las revoluciones no son acontecimientos, sino procesos. El de la Revolución Industrial fue, comparándolo con los de otras revoluciones, bastante largo. La mayoría de los estudiosos lo fechan, aproximadamente, entre 1760 y 1830 . Hubo algunos años de actividad febril, tal como el annus mirabilis de 1769, cuando, en cinco meses, James Watt y Richard Arkwrigth patentaron dos de los inventos más importantes realizados hasta la fecha, pero la Revolución Industrial careció de los apogeos espectaculares de las revoluciones políticas. Algunos de los mejores historiadores del período han evitado completamente la utilización del término (Clapham, 1926, p. 38; Heaton, 1948). A los que afirman como Hartwell (1971) que la Revolución Industrial fue una «gran discontinuidad» se oponen los de la escuela gradualista, cuyo punto de vista fue bien expresado por Hughes (1970, p. 45). Hughes encuentra difícil considerar brusco algo que duró tanto tiempo: «no podemos considerar los acontecimientos de los últimos setenta años como algo repentino. En Gran Bretaña, los setenta años comprendidos entre 1760 y 1830 no transcurrieron más rápidamente».

Pero el término ha prendido, y no sólo porque, como dijo Ashton, se utiliza ahora tan generalizadamente que sería pedante proponer un sustituto (Ashton, 1948, p. 4). La razón principal por la que consideramos la Revolución Industrial como una «revolución» es porque sus efectos fueron tan profundos que, incluso aunque los dividamos por setenta, el cambio anual fue lo bastante trascendental como para empequeñecer cualquier transformación económica de Gran Bretaña desde la peste negra. Mantoux (1928, p. 25) indicó que el término revolución es apropiado aún cuando «pocas revoluciones políticas habían tenido consecuencias de tanto alcance». El cambio económico y el aumento de la productividad no eran nuevos en 1760. Pero a diferencia de períodos anteriores, tales como la ola de cambio tecnológico que barrió Gran Bretaña en el siglo posterior a 1540 , el crecimiento fue sostenido y, más aún, acelerado. $Y$ es esta celeridad la que se materializa en metáforas de crecimiento discontinuo y brusco, como el «despegue» de W. Rostow y la "gran aceleración» de Alexander Gerschenkron.

Se pueden distinguir cuatro escuelas de pensamiento diferentes acerca de lo que realmente importó en la Revolución Industrial. Estas escuelas difieren 
en su énfasis sobre las diversas áreas de cambio, aunque muchos de los trabajos más significativos no se pueden clasificar ${ }^{8}$.

1. La escuela del cambio social. Esta escuela considera que la Revolución Industrial fue, ante todo, un cambio en el modo en que se realizaban las transacciones económicas entre las personas. La aparición de mercados de bienes y factores de producción establecidos, competitivos e impersonales, constituye la base de este punto de vista. Toynbee $(1884$, p. 58$)$ escribió que «la esencia de la Revolución Industrial se encuentra en la sustitución de las normas medievales, que previamente habían controlado la producción y la distribución de la riqueza, por la competencia». Karl Polanyi (1944, p. 40) juzgó el nacimiento de la economía de mercado como el hecho verdaderamente fundamental, ante lo que todo lo demás era secundario.

2. La escuela de la organización industrial. Esta escuela destaca la estructura y el tamaño de la empresa; en otras palabras, el nacimiento del sistema fabril. Se centra en la aparición de grandes empresas, fábricas, minas, ferrocarriles e incluso de grandes tiendas al por menor en las que, por lo general, se concentraba a los trabajadores bajo un mismo techo, sujetos a una disciplina y a un control de calidad. Mantoux (1928) es el clásico ejemplo, aunque la interpretación de Karl Marx de la aparición de las Machinofactures también pertenece a esta escuela, como, asimismo, pertenecen algunos escritores radicales actuales (Marglin, 1974-75). Una obra reciente que discute la Revolución Industrial desde este punto de vista es la de Pollard (1965). Relacionada con esta interpretación se encuentra una que hace hincapié en la distinción entre el capital circulante y el capital fijo. Algunos economistas (Hicks, 1969, pp. 142-143; Ranis y Fei, 1969) han definido la Revolución Industrial como el paso de una economía en la que el capital era, en su mayor parte, circulante (por ejemplo, semillas en la agricultura y materias primas en la industria doméstica), a otra en la que el capital era fundamentalmente fijo (por ejemplo, maquinaria, minas y estructuras).

3. La escuela macroeconómica. La escuela macroeconómica, muy influida por los escritos de Simon Kuznets, subraya la importancia de variables agregadas tales como el crecimiento de la renta nacional, la tasa de formación de capital o la tasa de inversión agregada, o el crecimiento y la composición de la mano de obra. Rostow (1960) y Deane y Cole (1969) son ejemplos significativos de esta escuela, y su influencia se ha extendido a personas que no son economistas (por ejemplo, Perkins, 1969). Algunos escritores como Gerschenkron (1962) agregan a nivel sectorial, prefiriendo tratar de la tasa de

' Lo que sigue está inspirado en Hartwell (1971, pp. 143-154), aunque la clasificaciớn que hago difiere considerablemente. 
crecimiento del sector manufacturero más que del crecimiento de toda la economía. La mayor parte de la Nueva Historia Económica propende a pertenecer a esta escuela, ya que por su misma naturaleza tiende a plantear cuestiones sobre grandes colectivos y no sobre individuos aislados (Fogel, 1983 a, p. 28).

4. La escuela tecnológica. Esta escuela considera que los cambios en la tecnología priman sobre todos los demás cambios, y se centra, por lo tanto, en la invención y en la difusión de los nuevos conocimientos tecnológicos. Por supuesto que la tecnología es algo más que una colección de simples «artilugios»: abarca la organización del trabajo, la manipulación del consumidor, las técnicas de comercialización y distribución, etc. El libro más influyente de esta escuela es el de Landes (1969a).

La cronología exacta de la Revolución Industrial difiere según las escuelas. Desde un punto de vista tecnológico, los cambios más espectaculares sucedieron en el período 1760-1800, mientras que los años 1800-1830 (a pesar de algunos inventos importantes) deben considerarse como un período de consolidación. Sin embargo, investigaciones recientes (Harley, 1982; Crafts, 1983) han mostrado que, antes de 1820, los efectos agregados de la Revolución Industrial en la economía o en el sector industrial en su totalidad no fueron abrumadores. Así, es posible distinguir dos Revoluciones Industriales: la ola de invenciones que se produjo en el último tercio del siglo xvirI y los cambios en el conjunto de la economía, acompañados por un rápido crecimiento del sector industrial, que se volvieron dominantes después de 1815. Aunque la segunda revolución no hubiera acaecido sin la primera, los autores más recientes han insistido en que los cambios a nivel agregado fueron más lentos y se produjeron más tarde que lo que se había creído hasta ahora, lo que cuestiona el momento en que se inició la Revolución Industrial en las décadas de 1760 y $1770^{9}$.

Este nuevo punto de vista sobre la Revolución Industrial se basa, en parte, en la simple verdad aritmética de que la tasa de crecimiento de la renta nacional o de la producción industrial es igual a la suma ponderada de las tasas de crecimiento de sus componentes. Aunque algunas industrias, como la del algodón, crecieron a un ritmo espectacular, éstas eran inicialmente pequeñas, por lo que su efecto en el total fue bastante modesto. La ponderación adecuada de las industrias más dinámicas ha llevado, pues, a estimaciones más conservadoras de la tasa de crecimiento industrial agregado. Además, los años críticos de la Revolución Industrial coincidieron parcialmente con las guerras revolucionarias y napoleónicas, cuyos efectos económicos contaminaron su his-

- La mayoría de los autores han rechazado el punto de vista anterior, propuesto por Deane y Cole, que fecha el comienzo de la Revolución Industrial en 1740. 
toria (Hueckel, 1973; Mokyr y Savin, 1976; Williamson, 1984). En términos de renta per cápita y de otros agregados económicos, la Revolución Industrial fue al principio relativamente reducida y localizada. Sólo una pequeña minoría se vio afectada de modo significativo. No hay que sorprenderse, pues, de que este fenómeno pareciera menos prometedor a los contemporáneos que a los historiadores, incluyendo a economistas políticos que deberían haberse dado cuenta de lo que sucedía. Como han señalado McCloskey (1981) y North (1981, p. 160), ni Adam Smith ni Ricardo (y, menos aún, Malthus) tenían algo más que una mera sospecha de la revolución que se estaba produciendo a su alrededor ${ }^{10}$.

El descubrimiento de que los efectos macroeconómicos de la Revolución Industrial no fueron abrumadores antes de 1820 no es realmente sorprendente. Es conveniente considerar a Gran Bretaña, durante la Revolución Industrial, como un sistema dual en que coexistían dos economías. Una era la tradicional, que, aunque no se hallaba estancada, se desarrollaba gradualmente siguiendo pautas convencionales, con un lento crecimiento de la productividad y con aumentos, asimismo lentos, de la relación capital-trabajo. Este sector abarcaba a la agricultura, la construcción, la industria doméstica y la mayoría de los «oficios" tradicionales, que ahora se clasificarían como industriales, pero que con anterioridad al siglo xvIII se consideraban parcialmente comerciales: panaderos, molineros, sastres, zapateros, herreros, curtidores y otros artesanos. El sector moderno se componía de las industrias del algodón, hierro y maquinaria, de la minería, del transporte y de otros bienes de consumo, como la alfarería y el papel. Sin embargo, al principio sólo se modernizaron segmentos de estos sectores, de modo que el dualismo existía dentro, así como entre las diferentes industrias, lo que hace que los cálculos sobre el funcionamiento del sector moderno sean bastante complicados ${ }^{11}$. Según las estimaciones de

${ }^{10}$ El panorama cambia cuando nos apartamos de las «estrellas» de la economía política clásica. En 1814, por ejemplo, Patrick Colquhoun escribió sobre «la acumulación de la propiedad que se ha extendido más allá de lo concebible y que (durante una guerra con gastos sin precedentes) ha crecido más rápidamente de lo que podían haber imaginado las mentes más optimistas... la prosperidad de la nación británica se ha alcanzado con una celeridad que carece de antecedentes, en especial en los últimos sesenta años» (Colquhoun, 1815, p. 49). El ingeniero y científico francés Sadi Carnot atribuyó, en 1824, la prosperidad y el poder británicos sólo a la máquina de vapor, y comparó la importancia de la máquina de vapor con la del sector de transportes en su totalidad.

"Una idea aproximada de las diferencias entre los dos sectores se puede obtener com parando las tasas de crecimiento de la producción anteriores a 1760 y las comprendidas entre 1760 y 1800 . La producción de algodón, por ejemplo, se incrementó en términos reales en un 1,37 por 100 anual entre 1700 y 1760 , y en un 7,57 por 100 entre 1760 y 1800. En la producción de hierro, las tasas de crecimiento fueron de un 0,60 por 100 y de un 4,10 por 100 , respectivamente. La aceleración fue mucho menos marcada en dos industrias tradicionales: en la tejeduría de hilo, las tasas de crecimiento fueron de un 1,25 por 100 y de un 1,44 por 100 , y en el cuero, de un 0,25 por 100 y de un 0,57 por 100, respectivamente (todos los datos están tomados de Crafts, 1983, pp. 6-7). 
McCloskey (1980), el sector tradicional era grande, si bien se hallaba en proceso de reducción. La magnitud media de la agricultura y de «los otros» oficios tradicionales entre 1780 y 1860 era de un 79 por 100 de la economía británica, lo que sugiere que es probable que en 1760 hubieran constituido un 90 por 100 de dicha economía. McCloskey calcula que el crecimiento de la productividad en este sector era de alrededor de un 0,6 por 100 anual. En el mismo período la productividad del sector moderno aumentó a un ritmo anual de un 1,8 por 100 .

Los modelos de crecimiento bisectoriales suponen que los cambios bruscos en la economía, en su conjunto, son una imposibilidad matemática. Aun cuando las transformaciones en el mismo sector moderno fueran discontinuas, su participación en la economía sólo se incrementaría gradualmente, en tanto que el sector tradicional perdería terreno muy lentamente. Con el tiempo, la fuerza de las tasas acumuladas de crecimiento fue tal que el sector moderno engulló a la economía entera. ¿Cuánto tiempo duró este período? Un ejemplo numérico resulta ilustrativo. Consideremos dos sectores en una economía hipotética, uno de los cuales (el sector moderno) crece a una tasa anual de un 4 por 100 , mientras que el otro (el sector tradicional) lo hace a un ritmo de un 1 por 100 al año ${ }^{12}$. Supongamos que, inicialmente, el sector moderno representa el 10 por 100 de la producción total. Transcurridos treinta años de «crecimiento dual» la participación del sector moderno se habrá incrementado hasta un 21 por 100 , y después de cincuenta años hasta un tercio. Sólo al cabo de setenta y cuatro años los dos sectores serían del mismo tamaño, y un siglo después del punto inicial el sector tradicional se habría reducido alrededor de un 31 por 100 de la economía. La economía británica, en su conjunto, cambió mucho más lentamente que sus partes más dinámicas, ya que los sectores con un crecimiento más lento atenuaron su desarrollo (Pollard, 1981, p. 39). Estas cifras cuadran bien con la documentación que poseemos, e indican que es poco sorprendente que se tuviera que llegar hasta 1830 ó 1840 para que se sintieran los efectos de la Revolución Industrial en el conjunto de la economía.

${ }^{12}$ Nótese que estas tasas difieren de las presentadas por McCloskey, ya que lo que es relevante aquí es el crecimiento de la producción total y no el de la productividad. La tasa de crecimiento media de «los productos manufacturados, la mineria y la construcción» entre 1801-1811 y 1851-1861 fue de un 3,57 por 100, mientras que la de «la agricultura, silvicultura y pesca" creció a un ritmo de un 1,5 por 100 anual (Deane y Cole, 1969, p. 170). En las últimas décadas del siglo xvin, la producción industrial aumentó, según los cálculos de Crafts, en un 2,11 por 100 anual, y la producción agrícola en un 0,75 por 100 . Crafts ha revisado, asimismo, las cifras de Deane y Cole para el siglo xIX, pero las diferencias no son lo suficientemente grandes como para afectar lo señalado aquí. Como se indicó anteriormente, la tasa de crecimiento del «sector moderno» debe haber sido más rápida que la de la «industria». Por ejemplo, el consumo de algodón - la materia prima por excelencia de la industria moderna- se incrementó a un ritmo anual del 10,8 por 100 entre 1780 y 1800 , y a una tasa de un 5,4 por 100 entre 1800 y 1840 . 
En realidad, la modernidad de las industrias y de las empresas fue algo continuo más que dicotómico, $y$, por este motivo, el ejemplo es muy esquemático. Asimismo, simplifica lo que sucedió realmente al no permitir que el crecimiento de los sectores moderno y tradicional se afecten mutuamente. La coexistencia de lo nuevo y de lo antiguo es importante, y la interacción de los dos sectores influyó mucho en el crecimiento del agregado. Si bien el cambio tecnológico del sector tradicional fue lento comparativamente, sus técnicas de producción se vieron afectadas por lo que ocurrió en el sector moderno. Por ejemplo, la tecnología de la construcción puede haberse transformado paulatinamente, pero el rápido perfeccionamiento de la tecnología del transporte permitió el traslado de ladrillos por toda Gran Bretaña, posibilitando la construcción de edificios más baratos y mejores. La agricultura se benefició de muchas maneras de los desarrollos tecnológicos acaecidos en la industria manufacturera, entre los que figuraban la producción de arcilla y, posteriormente, de tuberías de desagüe y de diversas máquinas y aperos agrícolas. El alumbrado de gas, uno de los "grandes inventos» más ignorados, permitió a muchos artesanos del sector tradicional trabajar más horas y reducir el coste del trabajo nocturno (Falkus, 1982). Estos efectos de desbordamiento intersectoriales suponen que la distinción entre los sectores tradicional y moderno es, hasta cierto punto, arbitraria. La interacción de los dos sectores fue, por supuesto, recíproca. Desde el punto de vista del sector moderno, el sector tradicional fue importante porque determinó el entorno sociopolítico en el que operaban las nuevas industrias. $\mathrm{Y}$, aunque aquél era en su mayor parte autosuficiente en lo que se refiere a materias primas y a capital, dependía de éste para abastecerse de mano de obra. Además, como ha señalado Berg (1985), el sector tradicional no era del todo incapaz de generar progreso tecnológico. Algunos inventos, como la lanzadera volante y la máquina de hilar algodón, iban explícitamente dirigidos a incrementar la productividad de la industria doméstica. Incluso en la construcción, una de las industrias más conservadoras, se pueden establecer algunos aumentos en la productividad con anterioridad a 1830 debidos al perfeccionamiento de los materiales de construcción, que culminó con la invención del cemento Portland en 1824.

En cierto modo, la inclusión del concepto de dualidad en nuestro análisis de la Revolución Industrial responde a la pregunta de Hartwell (1971, p. 169) sobre si fue «la industria» o «la economía», es decir, si la Revolución Industrial debe considerarse como un cambio en la economía en su conjunto o si su análisis debe limitarse al sector manufacturero. El sector moderno no fue sólo industrial ni comprendió a toda la industria. Así, se puede considerar la Revolución Industrial como un triple acontecimiento en el que: $a$ ) un sector de la eçonomía sufrió una transformación muy rápida; $b$ ) este sector creció con más rapidez que el resto de la economía, de manera que su participación 
en la producción y en el empleo total aumentó (lo primero más rápidamente que lo segundo), y $c$ ) finalmente, el sector moderno influyó, asimismo, en el ritmo de desarrollo del sector tradicional. La economía creció, pero su composición sectorial también cambió. Estaba «madurando» (Mokyr, 1976 b). No era, por supuesto, toda la economía, aunque finalmente llegaría a serlo. Por este motivo, el medir las tasas de crecimiento agregado en la tradición de Kuznets no es, quizá, la mejor estrategia para intentar entender la Revolución Industrial, aunque tiene su interés. Los historiadores de esta revolución deben acordarse de la advertencia de Schumpeter (1939, p. 144) acerca de que las relaciones entre agregados son totalmente inadecuadas para enseñarnos nada acerca de la naturaleza de los procesos que determinan sus variaciones. Tomada literalmente, esta advertencia es ciertamente falsa, si bien sirve para recordarnos los rendimientos rápidamente decrecientes de los análisis agregados de la Revolución Industrial.

\section{Las causas de la Revolución Industrial}

¿Por qué se produjo una Revolución Industrial? Planteada de este modo, la pregunta no tiene contestación. Se han propuesto, sin embargo, algunas respuestas a versiones mejor enfocadas de la pregunta y, aunque un acuerdo total sigue estando lejano, la discusión es una de las más animadas de la literatura historiográfica. Algunos ejemplos de estas preguntas son: ¿Por qué se dio la Revolución Industrial en Gran Bretaña y no en Francia (o los Países Bajos, Alemania o España? ¿Por qué se inició en el último tercio del siglo xviII y no, por ejemplo, un siglo antes? ¿Podemos encontrar factores que se deban considerar como «condiciones previas necesarias» para que tuviera lugar la Revolución Industrial?

Empezando por la última pregunta, la noción de que ciertos cambios fueron una condición sine qua non para que se diera la Revolución Industrial se ha hecho cada vez más difícil de mantener (Gerschenkron, 1962, pp. 31-51). Algunos factores que estuvieron presentes en Gran Bretaña la facilitaron, y, en este sentido, se puede decir que fueron causales. Otros factores impidieron su progreso, y ésta avanzó a su pesar. Después de todo, los factores que no fueron necesarios ni suficientes para el resultado final pueden seguir considerándose causales. Por ejemplo, los ataques cardíacos provocan muertes, aunque no todas las muertes las provocan los ataques cardíacos y no todos los ataques son mortales. Los historiadores económicos han empezado a admitir cada vez más que el efecto positivo que el factor $X$ tuvo en la Revolución Industrial no le da derecho a que se le conceda status de «factor necesario». 
Se tiene que recurrir al análisis contrafactual, al menos implícitamente, para evaluar la indispensabilidad de los diferentes elementos ${ }^{13}$.

No está claro que la pregunta «¿Por qué Gran Bretaña?» sea necesariamente una buena manera de comprender la Revolución Industrial. Hay dos artículos que cuestionan seriamente este enfoque. El profesor Pollard (1973) -véase, también, su libro más reciente, Peaceful Conquest (1981, p. 41)ha insistido en que la pregunta "¿Por qué Gran Bretaña?» es inapropiada. Más que la habitual división de Europa en economías, que corresponden más o menos a entidades nacionales, Pollard prefiere una subdivisión en «regiones». La Revolución Industrial no fue un acontecimiento que tuvo lugar en determinadas economías nacionales, fue principalmente un asunto regional. Claro que Gran Bretaña tenía muchas regiones con condiciones favorables a la industrialización, pero, de ninguna manera, toda, o incluso la mayor parte de Gran Bretaña, se encontraba en una posición ventajosa. Algunas zonas del Continente europeo, tales como las provincias de Lieja y Flandes, al este de Bélgica; los departamentos del norte de Francia; Alsacia; partes de Suiza; la zona del Rin, en Alemania, y la región industrializada del este de Estados Unidos, sólo iban un poco a la zaga de Gran Bretaña en cuanto a desarrollo industrial, si bien las economías que las rodeaban (con la posible excepción de Bélgica) estaban en promedio menos desarrolladas que Gran Bretaña ${ }^{14}$.

Crafts (1977) plantea una crítica diferente a la pregunta «¿Por qué Gran Bretaña?». Crafts mantiene que hay un fuerte elemento de azar en la supremacía de Gran Bretaña, y que las condiciones existentes en Francia en vísperas de la Revolución Industrial eran tan favorables como las de Gran Bretaña.

${ }^{13} \mathrm{El}$ análisis contrafactual supone la creación de un mundo hipotético que nunca existió. Ayuda a contrastar la hipótesis de que el factor $X$ fue una condición necesaria para provocar el resultado $Y$, es decir, que en ausencia de $X, Y$ no se hubiera dado. Aunque a menudo se atribuye, o se critica, a la Nueva Historia Económica el haber introducido este modelo de análisis, éste ha sido siempre un instrumento básico de los historiadores tradicionales. Así, Craig (1980, p. 1) inicia su estudio magistral sobre la historia moderna de Alemania de la siguiente manera: «Es ciertamente innecesario pedir perdón por incluir al comienzo del libro el nombre de Bismarck. Si nunca hubiera llegado a lo más alto de la política prusiana, la unificación de Alemania se hubiera producido de todas maneras, pero... sin duda, no del mismo modo.»

${ }^{14}$ La crítica que hace Pollard de la economía nacional como la unidad de análisis no es probable que permanezca indiscutida. Los mejores argumentos para la elección de la nación-Estado como la unidad de análisis adecuada se siguen encontrando en Kuznets (1966, pp. 16-19), quien indica que las naciones comparten herencias e historias comunes $\mathrm{y}$, de este modo, la gente tiende a sentirse más interesada por su historia nacional que por las historias regionales. Además, las naciones-Estados compartieron un gobierno común, que es el órgano principal de toma de decisiones políticas, $\mathrm{y}$, en tanto que este gobierno afectó al desarrollo económico, la unidad bajo su jurisdicción debe ser la unidad de análisis. El hecho de que la mayor parte de nuestros datos se encuentren a nivel nacional (por ejemplo, estadísticas de comercio exterior, de ingresos fiscales, de salarios y precios) refleja estos argumentos. 
Así, el éxito final de Gran Bretaña es, en gran parte, inexplicable. Una buena analogía es el echar a cara o cruz una moneda: una vez que se ha lanzado al aire y que ha salido cara no tiene sentido explicar por qué ha sucedido. Sin embargo, este enfoque también se ha criticado (Rostow, 1977). Como escribió Hicks $(1969$, p. 5), «aunque tiene sentido pensar que la Revolución Industrial es un acontecimiento, es, asimismo, un fenómeno estadístico; es una tendencia general para la que la teoría es inequívocamente relevante». El «azar» que exaspera a Crafts es en parte un reflejo de la incapacidad de los economistas para construir modelos que expliquen grandes sucesos como la Revolución Industrial ${ }^{15}$. No obstante, tenemos que preguntar en qué se diferenciaba Gran Bretaña de las economías del Continente europeo para conseguir ir a la cabeza de la carrera por el liderazgo industrial.

\section{Factores geográficos}

La disponibilidad de riquezas minerales, en especial de carbón y de hierro, ha sido tradicionalmente una explicación popular y aparentemente convincente del éxito de Gran Bretaña, así como del fracaso de algunos industrializadores tardíos como los Países Bajos o Irlanda ${ }^{16}$. La importancia de la localización del carbón y del hierro es lógicamente correcta, pero de significación secundaria ${ }^{17}$. El carbón, aunque finalmente se convirtió en la principal fuente de energía de Europa, tenía unos buenos sustitutivos en la turba y la madera (para energía térmica) y en la energía hidráulica (para energía cinética). El hierro era mucho más difícil de sustituir, pero ya era un producto con el que se comerciaba internacionalmente antes de que la energía de vapor redujera los costes del transporte transatlántico a una fracción. En el período 17941796, Gran Bretaña importó un valor medio de 852.000 libras esterlinas de hierro y de mineral de hierro, la mayor parte de Suecia. La posterior depen-

${ }^{15}$ Existe una diferencia entre lanzar al aire una moneda sólo una vez y tener que explicar por qué salió cara, y echar la moneda al aire cien veces y explicar por qué salió cara noventa veces. En el segundo caso, el estudioso debe comprobar con meticulosidad si la moneda estaba trucada, es decir, debe buscar las fuerzas sistemáticas que determinaron los resultados. Por supuesto que esta analogía no es muy exacta, ya que los resultados observados (el éxito de Gran Bretaña en varias industrias y empresas) no eran -a diferencia de lanzar una moneda al aire- mutuamente independientes.

${ }^{16}$ Wrigley (1962) ha situado el abastecimiento de materias primas en el centro del escenario, pero no está claro si cree en el determinismo geográfico para explicar la Revolución Industrial en Gran Bretaña. Para él, el cambio fundamental fue el paso de la madera al carbón y al hierro. Aunque es un punto de vista interesante, no es un análisis de la Revolución Industrial, ya que este cambio se inició mucho antes de 1750 , y en la propia minería del carbón se dio un progreso relativamente pequeño, como ha señalado el mismo Wrigley.

${ }_{17}$ Algunas de las argumentaciones presentadas aquí se derivan de Mokyr (1980). 
dencia del hierro británico era, obviamente, una ventaja, aunque en su ausencia se podía haber seguido importando mineral de hierro sueco. Tras la invención del proceso Bessemer, Gran Bretaña importó grandes cantidades de hematites de Bilbao. Los ricos minerales de hierro de Suecia no le ayudaron a tener demasiado éxito en la modernización de su industria con anterioridad a 1850. La industria más dinámica de Gran Bretaña (la del algodón) dependía totalmente de importaciones para conseguir las materias primas. Suiza, Flandes y Alsacia son ejemplos de regiones que no estaban dotadas en abundancia de carbón y de hierro y, sin embargo, tuvieron éxito en la modernización de sus industrias.

Estas críticas de la explicación geográfica no se deben exagerar. Una región o una economía tenían que tener algo para producir bienes y servicios a costes competitivos. No hay duda de que no se puede absolver a la geografía por la carencia de desarrollo económico, por ejemplo en Groenlandia ${ }^{18}$. Sin embargo, en un análisis estático la importancia de las materias primas y del combustible no puede exceder su proporción en los costes totales de fabricación más los costes adicionales de transportar un sustitutivo ${ }^{19}$. Cuando se consideran modelos más dinámicos, la importancia de la riqueza mineral es menos fácil de evaluar. Cradwell (1972) ha escrito que «es probablemente cierto que... la cultura material de Europa se ha basado en la minería... las zonas mineras de Europa en la época medieval fueron centros de tecnología y de ciencia, así como de organización financiera y de empresa comercial», y enumera los inventores y hombres de negocios cuyas carreras estuvieron asociadas a la minería (p. 73). Wrigley (1962) ha hecho hincapié en la importancia de las minas de carbón en el desarrollo de la navegación de cabotaje, de los canales y de los ferrocarriles. Además, la minería del carbón generó más innovaciones técnicas que cualquier otra industria con anterioridad a la Revolución Industrial (Mason, 1962, p. 272). Los problemas encontrados en la minería condujeron al desarrollo de la máquina de vapor, así como al de bombas, raíles de hierro y otras invenciones en ingeniería hidráulica y de caminos. Los recursos naturales no sólo suministraron combustible y materias primas baratas, sino que también crearon externalidades tecnológicas que afectaron a otras actividades que no dependían de la localización. Gran Bretaña disfrutaba de una ventaja adicional gracias a la disponibilidad de la navegación de cabotaje, aunque finalmente se consideró que esta forma de transporte era inadecua-

"También se debe señalar que la geografía puede haber tenido mucha más importancia para explicar el desarrollo de Europa en su conjunto, comparado con el resto del continente euroasiático. Esta tesis se expone en un trabajo excepcionalmente original de Jones $(1981 b)$.

${ }^{19}$ Como indica Mokyr (1980, p. 441$)$, esta cifra es, en realidad, una cota superior, dado que no permite sustituciones del factor que aumenta de precio. 
da y se complementó con canales y carreteras, y más tarde con ferrocarriles.

Otra forma en que la geografía seleccionó a Gran Bretaña para que se convirtiera en el primer taller del mundo fue por el hecho de ser una isla y, por lo tanto, una fortaleza natural. Desde 1066 nadie ha logrado invadirla, y las únicas devastaciones militares que había sufrido el país se las había infligido él mismo. Pese a que algunos de los destrozos causados por las guerras civiles fueron severos, Gran Bretaña no sufrió guerras continuas como Bélgica, Polonia, el norte de Italia y grandes partes de Alemania. En consecuencia, nunca tuvo que gastar sumas exorbitantes en protegerse de los invasores extranjeros, y sólo una proporción, relativamente pequeña, de los mejores y más brillantes ciudadanos británicos desperdiciaron sus talentos y sus energías en carreras militares improductivas. Y más importante, Gran Bretaña consiguió permanecer apartada de la lucha real que tuvo lugar en los años cruciales comprendidos entre 1792 y 1814 . Es verdad que las guerras francesas y napoleónicas fueron costosas para este país, ya que disminuyeron la tasa de acumulación de capital comparada con la que podía haber sido. No obstante, la distancia entre Gran Bretaña y el Continente se hizo mayor en esos años. No importa si Gran Bretaña y Francia se encontraban, en 1780, en niveles semejantes de industrialización, como mantiene Crouzet (1976 b) y Crafts (1977), el hecho es que en 1815 Gran Bretaña llevaba mucha ventaja. Los impuestos, las levas, los daños directos de la guerra, las interrupciones del comercio y el derroche de energía y de talento en lo militar y lo político costaron al Continente europeo, por lo menos, un cuarto de siglo de desarrollo industrial, a pesar de los intentos de Napoleón de fomentar la modernización de la industria francesa. Gran Bretaña se libró de esto simplemente porque el ejército de Napoleón en Boulogne no consiguió cruzar el canal.

\section{Ciencia y tecnología}

Para la mayoría de los historiadores, el proceso tecnológico continúa siendo considerado, tras un siglo de debate, como uno de los motores fundamentales de la Revolución Industrial. Más adelante se discutiría si el análisis económico puede ayudar a comprender este proceso. Pero antes tenemos que plantearnos si los británicos eran, por algún motivo, mejores para adaptar las leyes de la naturaleza a las necesidades económicas. Un gran número de importantes invenciones realizadas en otros países se aplicaron con más éxito en Gran Bretaña. Entre éstas se encuentran el blanqueado con cloro, descubierto por el francés Claude Louis Berthollet (1785); el proceso de producción de sosa, de Nicholas Leblanc (1787); el alumbrado de gas, inventado conjuntamente 
por el francés Philippe Lebon y el escocés William Murdock (alrededor de 1798); el proceso de hilado mecánico del lino, de Philippe de Girard (alrededor de 1810); el famoso telar Jacquard (patentado en 1802); la técnica de conservación de frutas y verduras frescas, de François Appert (en 1795), y la fábrica de papel continuo descubierta por N. L. Robert (1798). Los inventores franceses experimentaron con barcos de vapor en la década de 1780 , inventaron el globo en 1783 (dos franceses fueron los primeros hombres que se elevaron sobre la tierra) y se les reconoció como los líderes mundiales en la ingeniería de puentes. Con todo, es digna de mención la facilidad con que muchas de estas innovaciones encontraron aplicaciones en las industrias británicas. Yendo en dirección opuesta, las exportaciones de tecnología británica al Continente encontraron muchos obstáculos. Algunos de ellos eran artificiales, creados por el gobierno británico en un intento de prohibir las exportaciones de maquinaria (derogados en 1843), si bien investigaciones recientes sugieren que la prohibición no fue muy efectiva (Jeremy, 1977). Sin embargo, la mayor parte de los retrasos en la difusión de la tecnología británica fueron causados por el atraso industrial del Continente. Se pedian ingenieros y técnicos de Gran Bretaña para operar y mantener la maquinaria en las primeras etapas, y los empresarios de más éxito del Continente tenían que recurrir a los consejos de los expertos de este país (Henderson, 1972).

Así, aunque los británicos no monopolizaron la producción de nuevas ideas tecnológicas, demostraron una increíble capacidad para ponerlas en práctica. Existía una cierta habilidad y tenacidad entre los inventores, los ingenieros y los hombres de negocios británicos, que es más difícil de detectar en ese momento en el Continente. Hombres como Smeaton, Brindley, Boulton, Arkwright, los Darby y los Walker tenían no sólo la capacidad de generar nuevas ideas, sino también, e igualmente importante, la de reconocer y valorar las de otras personas. Si los inventores, por un motivo u otro, eran incapaces de explotar sus inventos, otros muchos estaban siempre esperando para aprovechar cualquier oportunidad. Un buen ejemplo es el de la técnica del laminado y del pudelado para producir hierro forjado (en barras) desarrollado por Henry Cort en 1784, quizá la invención más importante de la Revolución Industrial. Cort era un contratista naval que consiguió resolver un problema que muchos otros habían intentado resolver, sin éxito, con anterioridad. Sin embargo, no triunfó como hombre de negocios. Como resultado del suicidio de uno de sus socios caducó la patente, y los fabricantes de hierro como Richard Crawshay, que previamente habían tenido que alquilar la patente de Cort, pudieron entonces usarla con libertad. Aunque Cort fracasó, en muy poco tiempo, su técnica se utilizó en toda Gran Bretaña ${ }^{20}$.

${ }^{20}$ Véase Ashton (1968, pp. 94-103). Hyde (1977, pp. 98-102) ha mostrado que Craw- 
Con todo, no debemos sacar conclusiones precipitadas sobre la sagacidad

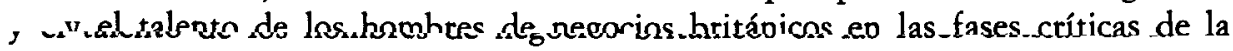
Revolución Industrial. Aunque se pueden hallar fácilmente ejemplos de empresarios que triunfaron, la historia empresarial puede ser engañosa, porque la documentación histórica se compone de supervivientes, que, de modo característico, tendían a ser los mejores y los más afortunados. La historia de la Revolución Industrial está llena de cadáveres de empresas que fracasaron, invenciones que no funcionaron bien, quiebras y decepciones ${ }^{21}$. Muchas compañías cuyo éxito inicial nutrió diariamente a la Revolución Industrial se malograron en etapas posteriores (Payne, 1974, pp. 35-38). No obstante, sólo conocemos los fracasos cuando las empresas triunfaron en un principio; las que nunca funcionaron bien son difíciles de encontrar. Los recursos - tanto físicos como empresariales - utilizados por estas empresas son uno de los costes ocultos de la Revolución Industrial que no se discuten normalmente. En general, estos costes no se deben exagerar: el equipo y las instalaciones de las compañías que quebraron no se perdieron totalmente, ya que otros propietarios los pusieron de nuevo en producción.

Un conjunto diferente de explicaciones del éxito de Gran Bretaña se centra en la posibilidad de que la educación, y en especial la educación científica, estuviera más avanzada que en otros países. Gran Bretaña era una sociedad alfabetizada, pero no mucho más que Holanda, Francia o Suecia (Cipolla, 1969, pp. 62-99; Sandberg, 1979). Sanderson (1972) ha mostrado que pocas ocupaciones requerían la capacidad de leer y escribir y que ésta no desempeñó un papel importante en la Revolución Industrial. A este respecto, se deben mantener separadas una serie de cuestiones. Una es factual: ¿aumentó el número de alfabetizados durante la Revolución Industrial? Schofield (1973) ha negado que se incrementara, pero E. G. West (1978) ha puesto en duda esta afirmación. Suponiendo que la alfabetización se elevara entre 1780 y 1840 , no hay ninguna certeza sobre la dirección en que se movió la causalidad. Mitch (1982), que discute en detalle la demanda y la oferta de alfabetización, trata de algunas de estas cuestiones. Concluye, matizadamente, que los incrementos en la demanda explican la mayor parte del aumento de la alfabetiza-

shay introdujo algunas mejoras importantes en el proceso de pudelado, que redujeron los costes sustancialmente.

${ }^{21}$ Algunos ejemplos famosos de fracasos incluyen el caso mencionado más arriba de Henry Cort, el de los inventores Lewis Paul y Charles Wyatt, que produjeron la primera máquina cardadora cilíndrica, y John Roebuck, el famoso fabricante de hierro. Existe al. guna incertidumbre en cuanto a las series de quiebras, pero no hay duda de que cientos de empresas fracasaban cada año. La serie de la London Gazette, citada por Ashton (1955, p. 254), daba un promedio de 495 quiebras en la década de 1780 y de 753 en la de 1790. Para una discusión de los documentos referentes a las quiebras y sus problemas, véase Marriner (1980). 
ción. En todo caso, hay pocos datos en su trabajo que sugieran que ésta fuera un importante elemènto causal del desarrollo índustrial. La industrialización afectó al tipo de educación, pero no toda la alfabetización se adquiría en la escuela, y no todas las escuelas se encaminaban a enseñar lectura, escritura y aritmética. El objetivo de la educación era, más bien, establecer ciertas actitudes morales que se consideraban importantes para los trabajadores (Field, 1979).

Por otra parte, R. A. Houston (1982 $a, 1982 b)$ ha comprobado que las tasas de alfabetización aumentaron sustancialmente en las tierras bajas de Escocia y en el norte de Inglaterra entre 1650 y 1750 . Y señala que no hubo necesariamente una conexión entre alfabetización e industrialización, pero que la alfabetización creciente de los artesanos y los comerciantes puede haber elevado indirectamente la productividad de los trabajadores industriales.

En lo que se refiere a la ciencia, Gran Bretaña contó con una serie de científicos y matemáticos eminentes en los siglos xvir y xviIr. Los estudiosos de la historia de la ciencia conocen los nombres de los grandes científicos británicos que vivieron durante la Revolución Industrial, tales como Priestley, Cavendish, Black, Herschel, Dalton, Davy y Faraday. Pero Gran Bretaña no poseía de ninguna manera un monopolio sobre la investigación científica, y las aportaciones de franceses, alemanes y norteamericanos al progreso de las ciencias naturales entre 1760 y 1850 fueron, por lo menos, tan importantes como las de los británicos. No existe, pues, una diferencia sistemática entre la ciencia británica y la del Continente europeo que corresponda al contraste en los logros económicos.

Además, la incidencia de la ciencia pura en el progreso tecnológico de este período fue, como mucho, modesta e indirecta (Cardwell, 1972; Mathias, 1972; Von Tunzelmann, 1981). Dicho de forma más sencilla, no mucho de lo que sabían los científicos podía haber llevado a importantes avances en la tecnología. De la lista de los cincuenta inventos más significativos efectuados entre 1760 y 1830 , sólo un puñado de ellos tuvieron una conexión directa con la ciencia o los científicos, e incluso en estos casos la relación fue ligera. No obstante, puede ser prematuro descartar completamente la importancia de la ciencia y de la comunidad científica. Comparados con los científicos de otros países, los británicos eran proclives a tener fuertes intereses prácticos. En Gran Bretaña, más que en ninguna parte, la interacción entre los científicos, los ingenieros y los hombres de negocios fue regular y se concretó en instituciones tales como la famosa Lunar Society de Birmingham. Quizá, también tenía la misma importancia el clima social, generalmente inhóspito, con el que se enfrentaron los inventores franceses. Dos destacados inventores franceses, Nicholas Leblanc, el inventor del proceso de fabricación de la sosa, y Aimé 
Argand (el inventor del quemador Argand, utilizado más tarde en el alumbrado de gas) se suicidaron después de que fracasaran sus intentos de sacar provecho a sus invenciones. Philippe de Girard, el inventor del proceso de hilado por vía húmeda, dejó su país al no materializarse un premio que le habían prometido por su invento. Barthelemy Thimonnier, el fabricante de uno de los primeros prototipos de la máquina de coser, murió pobre y amargado. En resumen, se puede mantener que Francia no fue nada agradecida con esos genios vitales que hicieron avanzar la tecnología a grandes saltos.

La ciencia francesa tendía a ser abstracta, formal y, a veces, apartada del mundo real. Las motivaciones de los científicos eran diferentes: en Francia la ciencia se practicaba por sí misma o servía a fines militares; en Gran Bretaña, por el contrario, muchos de los grandes científicos buscaban constantemente aplicaciones a la industria económicamente útiles $\mathrm{y}$, a ser posible, rentables. El químico Joseph Black, de Glasgow, constituye un ejemplo interesante. Se ha mantenido - siguiendo una afirmación realizada por el propio Black - que la idea crucial de James Watt de añadir un condensador separado a la máquina de vapor de Newcomen se inspiró en las enseñanzas de Black. Esta afirmación ha sido refutada. Sin embargo, Black fue un amigo de toda la vida de Watt, y su influencia se extendió a otras figuras claves de la industria, tales como James Keir, pionero de la industria química británica, y John Roebuck, fundador de la fundición de hierro Carron. El hecho de que Black intentara atribuirse el mérito del invento de Watt es, en sí mismo, significativo, ya que demuestra el deseo de los científicos de asociarse con el progreso industrial. La ciencia británica difería de la del Continente en que sus tradiciones se derivaban de Francis Bacon más que de la metodología, más matemática y formal, de Descartes. Bacon y sus seguidores más importantes, tales como Robert Boyle y Robert Hooke, subrayaron el hecho de que la «filosofía natural» tenía que ser beneficiosa para la sociedad, y que el empirismo baconiano era el medio natural para conseguir estos resultados ${ }^{22}$. Además, tanto en Inglaterra como en Escocia, se hicieron intentos de realizar aplicaciones directas de la ciencia a la industria. Por ejemplo, la fundación de la Royal Institution inspirada por el conde Rumford en 1799. Rumford había propuesto la creación de una institución para facilitar «la introducción general de los inventos mecánicos útiles y... la aplicación de la ciencia a los fines comunes de la vida». Unos pocos años antes, John Anderson había establecido en Glasgow (mediante su testamento) la Anderson Institution, que tenía un propósito similar. Este énfasis tan explícito en los aspectos útiles y pragmáticos de la ciencia parece, en este momento, una característica particularmente británica.

\footnotetext{
pp. 30-36).

22 Véanse
} 
Es, quizá, demasiado simple sostener que el progreso científico "causó» la Revolución Industrial, o viceversa. Los científicos y los ingenieros compartieron y reforzaron mutuamente una «fe racional en el orden y en los procesos físicos» (y) «un rechazo de todo lo que no se pudiera ver personalmente... y poner a la disposición de los demás» (Parker, 1979, p. 55). La ingeniería puede no haber sido capaz de emplear directamente ningún principio científico básico, pero aprendió de los científicos la importancia de la exactitud en la medida, del método experimental riguroso y del uso del cálculo y de las matemáticas. En Gran Bretaña, éstos estaban ansiosos de dar y los técnicos de recibir. Al mismo tiempo, se debe señalar que la ciencia no fue el único origen de la precisión y de la tecnología de la energía. Muchos de los ingenieros que desempeñaron papeles fundamentales en la Revolución Industrial se formaron en la fabricación de relojes y de instrumentos (Cardwell, 1972, p. 16).

\section{Politica y Estado}

Las instituciones políticas británicas se diferenciaban mucho de las de la mayoría de los países europeos. El pensamiento reciente de los economistas ha tendido a dar un énfasis considerable a los elementos políticos. Douglas C. North (1981, pp. 147 y 158-170) ha sostenido que la Revolución Industrial en Gran Bretaña fue facilitada por una mejor especificación de los derechos de propiedad, que llevaron a una organización económica más eficiente. La relación entre los derechos de propiedad y el crecimiento económico se basa en la mayor eficiencia de la asignación de recursos que resulta de la igualación de las tasas de rendimiento y de los costes privados y los sociales. Los derechos de propiedad en la innovación (patentes y marcas), la mejor protección de los tribunales y de la policía y la ausencia de impuestos confiscatorios son ejemplos de cómo el mismo fenómeno puede elevar la tasa de actividad innovadora y de acumulación de capital. North hace hincapié en que los derechos de propiedad bien especificados no son lo mismo que el laissez-faire. Los primeros eran mucho más importantes, dado que reducían los costes de transacción y, por tanto, permitían mercados más integrados, unos niveles más altos de especialización y la realización de economías de escala.

North mantiene que la especificación eficiente de los derechos de propiedad se derivó de la victoria del Parlamento sobre los Estuardos en 1650 y, de nuevo, en 1688 (p. 156). El Parlamento fue capaz de impedir que la $\mathrm{Co}$ rona impusiera contribuciones arbitrarias e imprevisibles mediante la conce- 
sión de monopolios y privilegios impositivos a ciertos individuos. «Si no se hubiera dado ese cambio [de poder de la Corona al Parlamento] la historia económica de Gran Bretaña hubiera sido muy diferente», escribe North ${ }^{23}$. El punto de vista expuesto por Mancur Olson (1982), aunque con un énfasis distinto, es igualmente inequívoco en su valoración del papel de la política en el período de la Revolución Industrial en Gran Bretaña. La teoría del crecimiento económico de Olson se basa en la idea de que los organismos políticos están sujetos a grupos de presión que persiguen el interés económico de sus miembros, incluso a expensas de la sociedad en su conjunto. Así, Olson asocia períodos de éxito económico, como la Revolución Industrial, con la relativa debilidad de estos grupos de presión. Según Olson, en Gran Bretaña no existieron, durante la Revolución Industrial, marcadas diferencias de clase, y, en comparación, era una sociedad móvil desde el punto de vista social, de manera que la lealtad a un determinado grupo de presión no era aún muy fuerte. Además, las guerras civiles del siglo xvir habían creado un gobierno estable a nivel nacional, que convirtió al país en una gran unidad jurisdiccional, en la que era difícil organizar grupos de presión perniciosos (Olson, 1982, pp. $78-83$ y 128$)^{24}$.

¿Fue Gran Bretaña una economía de laissez-faire?, y ¿es, por tanto, la Revolución Industrial un monumento al potencial económico de la libre empresa? Quizá, aunque se deben hacer algunas matizaciones. En términos absolutos, Gran Bretaña no era una pura economía de laissez-faire. Pero los absolutos no son demasiados útiles aquí. Comparado con Prusia, España o el Imperio de los Habsburgos, el gobierno británico dejó generalmente en paz a los hombres de negocios para que llevaran sus asuntos, y pocas veces se aven-

${ }^{23}$ El punto de vista de North no permanecerá indiscutido. El desarrollo de derechos de propiedad eficientes en Gran Bretaña se encuentra muy relacionado con el desarrollo gradual del derecho consuetudinario de precedentes judiciales, y el papel del cambio político en él es discutible. Después de 1688, el Parlamento británico elevó los impuestos de todas las formas posibles, imponiendo a veces gravámenes muy impopulares, como el impuesto sobre la renta de 1799 . Sin embargo, pocos pondrían en duda que el éxito de la industrialización requiere alguna forma de régimen político compatible con la modernización económica, aunque no es necesario que sea similar al de Gran Bretaña.

${ }^{24}$ Algunas de las afirmaciones históricas de Olson invitan a la controversia. Escribe (p. 128) que las guerras civiles británicas «desanimaron la inversión a largo plazo» (una deducción posible, pero totalmente indocumentada), pero que "pocas décadas después de que se terminara [la guerra civil] era evidente que se había restablecido en Gran Bretaña un gobierno a nivel nacional, y que la Revolución Industrial estaba en marcha». «Estar en marcha» es, por supuesto, una frase ambigua, pero entre la Restauración y el comienzo de la Revolución Industrial, como se define normalmente, había transcurrido al menos un siglo (no unas «pocas décadas»). De aquí que el modelo de Olson pueda necesitar alguna investigación adicional. No obstante, la originalidad de este enfoque y la increíble ambición de su modelo han añadido, ciertamente, una bienvenida dimensión política a la historiografía de la Revolución Industrial. 
turó él mismo en empresas comerciales e industriales. El mercantilismo nunca alcanzó en Gran Bretaña la forma extrema de Francia, bajo Colbert, o de Prusia, con Federico el Grande, en donde el Estado consideraba sencillamente que la empresa privada era incompetente e intervenía, en general sin éxito, en sus asuntos. En el apogeo de la Revolución Industrial, incluso proyectos sociales de envergadura, que muchas otras sociedades hubieran considerado que contaban con las suficientes ventajas públicas como para justificar la intervención directa del Estado, se dejaban en Gran Bretaña en manos de la empresa privada. En este país, las carreteras, los canales y los ferrocarriles se construyeron sin ayuda directa del Estado, y las escuelas eran privadas. Incluso las formas de ayuda estatal más ilustradas, como las políticas de Guillermo I de Orange, en los Países Bajos, o los sansimonianos, en la Francia del Segundo Imperio, estuvieron notoriamente ausentes de Gran Bretaña. Antes de finales del siglo xIX, el gobierno británico se abstuvo claramente de invadir lo que él consideraba que era la esfera de la libre empresa.

Las regulaciones y las normas, la mayor parte de ellas reliquias de los tiempos de los Tudor y de los Estuardo, permanecían vigentes, pero el consenso general entre los historiadores actuales es que éstas rara vez se hacían respetar. A medida que la economía se hacía más refinada y los mercados más complejos, la capacidad del gobierno para regular y controlar asuntos tales como la calidad del pan o la duración de los contratos de los aprendices desapareció de forma efectiva (Ashton, 1948, p. 95). El gobierno central controlaba el comercio exterior, pero la mayor parte de la administración interna se dejó en manos de las autoridades locales. Los magistrados locales se ocupaban del comercio interior, de la regulación de los mercados de trabajo y de tierras, de la justicia, la policía, la conservación de los caminos rurales y de la beneficencia. En tanto que, en principio, estas autoridades podían tener un poder considerable, en general optaban por no ejercerlo. Esta política de laissez-faire de facto procedía no tanto de principios libertarios como del propio interés de la gente que ya poseía riquezas y que estaba acumulando más. Ignorando y evadiendo las regulaciones, más que aboliéndolas, Gran Bretaña se encaminó hacia una sociedad de libre mercado. A excepción de sus críticas contra la intervención estatal en el comercio exterior, La riqueza de las naciones estaba anticuada en un siglo cuando se publicó: lo que recomendaba ya se había logrado en su mayor parte (Perkin, 1969, p. 65). Algunas regulaciones eran más difíciles de pasar por alto que otras. Algunos historiadores piensan que las leyes contra la usura, que establecían un techo a todos los tipos de interés privados, tuvieron un efecto considerable sobre la asignación de recursos (Ashton, 1955, pp. 27-28; Williamson, 1984). No obstante, se dispone de evidencia que indica que las leyes contra la usura se evadieron extensamen- 
te ${ }^{25}$. La ley del calicó, aprobada en 1721 y abolida en 1774 , a la que a veces se le atribuye el haber estimulado el cambio técnico en la industria del algodón, contaba con importantes rendijas que eximían al fustán de las prohibiciones. Dado que los fustantes se parecían mucho a los calicós, la prohibición se eludió generalizadamente, aunque era una molestia. La Bubble Act, aprobada en 1720, exigía una ley privada del Parlamento para constituir una sociedad anónima. No obstante, los estudiosos actuales se han ido dando cuenta de que también este impedimento era más un estorbo que un obstáculo real a la actividad comercial (Cottrell, 1980, p. 10). Parece que sucedía lo mismo con las restricciones a la exportación de maquinaria textil y a la emigración de artesanos (Jeremy, 1977). Unos cuantos monopolios gubernamentales, como la East India Company (Compañía de las Indias Orientales), sobrevivieron hasta bien entrado el siglo xIx. Además, mediaba un gran abismo entre el libre comercio y la realidad. Durante las guerras napoleónicas, los aranceles subieron a niveles sin precedentes (alcanzando el máximo en 1822 con un 64 por 100 del valor de las importaciones). En 1825 se inició una lenta tendencia hacia aranceles más bajos, lo que culminó en la abolición de las Leyes de Cereales en 1846 y en la derogación de las Leyes de Navegación, que habían impedido que los buques de carga extranjeros transportaran mercancías británicas, en 1849-1854. Claro está, los aranceles y las restricciones a la navegación también fueron evadidos extensamente ${ }^{26}$.

Otra área en la que fue importante la intervención gubernamental y en la que la ley estuvo muy lejos de ser letra muerta fue la beneficencia. En esto la diferencia entre Gran Bretaña y el Continente europeo es impresionante. En ningún sitio del mundo se puede encontrar un sistema de beneficencia obligatorio tan bien organizado como el inglés. La vieja Ley de Pobres, llamada a veces erróneamente Speenbamland (de hecho, el sistema Speenbamland de subsidios para complementar los salarios se utilizó en una minoría de condados), tenía muy mala prensa. En su contra se han formulado dos críticas

25 Aunque las leyes contra la usura no pudieron mantener los tipos de interés privados en un 5 por 100 en todo momento, distorsionaron el mercado de capitales de un modo sustancial. Una comisión parlamentaria concluyó, en 1818, que «las leyes que regulan o restringen los tipos de interés se han evadido extensamente y han fracasado en su intento de imponer un máximo a dicho tipo... En los últimos años, debido a los excesos constantes del tipo de interés de mercado por encima del tipo de interés marcado por la ley, se han incrementado los gastos incurridos por los prestatarios con garantía hipotecaria (Gran Bretaña, 1818, vol. VI, p. 141). Véanse también Pressnell (1956, pp. 95, 318, 368 y 428) y Cottrell (1980, pp. 7-8 y 13).

26 El contrabando era generalizado, como se puede comprobar por el hecho de que en ocasiones, cuando se reducian sustancialmente los aranceles, las importaciones aumentaban en proporciones mucho mayores. Por ejemplo, cuando en 1808 se redujo en dos tercios el arancel sobre el café, las importaciones subieron de 1,07 millones a 9,3 millones de libras en 1809. 
principales. Una era la queja malthusiana de que la beneficencia reducía el incentivo a trabajar e incrementaba la tasa de natalidad. La otra crítica, ya mencionada por Adam Smith (1776, p. 157), era que la Ley de Pobres (y en especial las leyes de asentamientos) obstaculizaba el libre movimiento de la mano de obra, dificultando, así, su distribución en una sociedad en la que los mercados de trabajo desempeñaban un papel creciente (Polanyi, 1944, pp. 77 102; Ashton, 1948, p. 111).

Estas críticas no han tenido suerte en años recientes. En efecto, parece probable que los efectos de las Leyes de Pobres en la Revolución Industrial no fueron tan negativos como se solía pensar. James Huzel $(1969,1980)$ ha atacado el argumento demográfico de que las Leyes de Pobres fomentaban grandes familias, y muchos consideraban que éste era otro mito malthusiano refutado. No obstante, en un artículo reciente, Boyer (1986) ha resucitado el punto de vista malthusiano mostrando que los datos utilizados por Huzel son, en realidad, inconsistentes con su crítica. Respecto a los efectos sobre el incentivo a trabajar, lamentado por los malthusianos, los trabajos de Pollard (1978, pp. 109-110) y de George Boyer (1983) han reforzado recientemente la investigación llevada a cabo por Blaug en los años sesenta. Estos autores argumentan que la causalidad fue en la dirección opuesta: los pagos en concepto de ayuda salarial se efectuaron en zonas que sufrían paro estacional, lo que explica la relación del sistema Speenhamland con las zonas agrícolas de Inglaterra. El que la vieja Ley de Pobres fuera de alguna manera responsable de la creación de un ejército de mendigos sanos sigue estando poco claro y se encuentra a la espera de nuevas investigaciones ${ }^{27}$. En lo que se refiere a la inmovilidad geográfica impuesta por las leyes de asentamiento, la ley de derogación de la vieja Ley de Pobres de 1795 [35 Geo. III (1795), c. 101], que prohibía expresamente la expulsión de inmigrantes pobres a menos que se convirtiesen realmente en una carga para el municipio, la mitigó en parte. Incluso antes de 1795 , el sistema «no era, de ningún modo, tal freno a la movilidad de los trabajadores, como supusieron algunos escritores anteriores», dado que la posibilidad de expulsión se ejercía de manera fortuita y casual (Styles, 1963, p. 62). Algunas opiniones contemporáneas están de acuerdo con estos resultados. Sir. F. M. Eden, cuya opinión, según Redford, tenía «tanto peso como la de Adam Smith», consideraba que las leyes de asentamiento se hicieron cumplir de forma demasiado poco rigurosa como para constituir el obstáculo a la movilidad alegado por Adam Smith (Redford, 1964, p. 85) ${ }^{28}$.

${ }^{27}$ McCloskey (1973) ha mostrado que los complementos a los salarios pagados bajo la vieja Ley de Pobres redujeron probablemente la oferta de mano de obra y, así, pudieron haber elevado los salarios, aunque la magnitud de este efecto no está clara.

2a Taylor (1969), que lanza una andanada contra la Nueva Historia Económica de la vieja Ley de Pobres, no está de acuerdo con Styles, pero la falta de evidencia hace que 
Quizá, el mecanismo principal por el que las leyes de asentamiento desanimaron las migraciones fue por su enorme complejidad y por la incertidumbre que su aplicación irregular suponía para cualquiera que estuviera pensando en emigrar. No obstante, dado que la migración era una empresa arriesgada en estas circunstancias, está muy lejos de ser evidente hasta qué punto la vieja Ley de Pobres empeoraba la situación ${ }^{29}$.

En efecto, se puede mantener que las Leyes de Pobres, pese a sus obvios fallos (en especial su falta de uniformidad), pueden haber tenido algunos efectos positivos globales en la Revolución Industrial. Una comparación con Irlanda, que no tuvo un sistema formal de beneficencia antes de 1838 , lo confirma (Solar, 1983; Mokyr, 1983). La red social proporcionada por las Leyes de Pobres permitió a los ingleses correr riesgos de un modo que hubiera sido imprudente en Irlanda, en donde el morirse de hambre seguía siendo más que posible. En sociedades que no tenían estas leyes eran comunes las formas de seguro individual, tales como grandes familias y activos líquidos, mientras que en Inglaterra, aún los «peores casos», rara vez suponían hambre real. El sistema Speenhamland garantizaba una mano de obra regular en las épocas con más trabajo en la agricultura. Se puede efectuar una argumentación similar para la industria manufacturera: se podía despedir a los trabajadores en los períodos de crisis sin miedo a que la mano de obra emigrara o pasara hambre. Los patronos irlandeses, por otra parte, se quejaban de que tenían que continuar pagando a los trabajadores durante las crisis o se arriesgaban a perderlos (Mokyr, 1983, p. 227). Además, la práctica del aprendizaje de pobres y la contratación de trabajadores fabriles en los asilos de pobres llevados por los administradores locales de la Ley de Pobres constituyeron, con anterioridad a 1800 , una importante fuente de mano de obra para las fábricas, especialmente las rurales y las que se encontraban en pequeñas ciudades ${ }^{30}$. Todo esto no

su ataque sea poco efectivo. Su queja de que la ley de 1795 no supuso un impulso para mejorar la movilidad de la mano de obra («la ley puede haber sido más fácil de cambiar que los hábitos mentales») tampoco tiene fundamento.

${ }^{29}$ En 1832, la emigración fue más importante en municipios con el sistema Speenhamland, que pagaban subsidios para ayuda salarial o subsidios para niños en Kent, que en municipios que no tenían este sistema (Huzel, 1980, pp. 375-378).

30 Algunas de las transacciones entre las autoridades de la Ley de Pobres y los propietarios de fábricas recordaban al tráfico de esclavos; por ejemplo, la compra de setenta niños del municipio de Clerkenwell por Samuel Oldknow en 1796 (Mantoux, 1928, p. 411). Pollard (1965, pp. 194-195) cita la hipócrita afirmación de algunos conocidos usuarios de mano de obra infantil de que estos aprendices pobres eran «más caros» que la mano de obra asalariada, y de que los empleaban porque era un deber social. Para un punto de vista semejante, véase Collier $(1964$, p. 45$)$. Con frecuencia se enviaba a los agentes de contratación a recorrer los alrededores en busca de mano de obra de los asilos de pobres, y algunos de estos niños se traían de la otra punta del país, lo que indica que para algunos industriales los aprendices pobres eran, en realidad, un tipo de mano de obra barata y satisfactoria. 
quiere decir, por supuesto, que las Leyes de Pobres «causaran» de algún modo la Revolución Industrial. Pero parece razonable suponer que su efecto neto no fue tan negativo como se ha sostenido, y que pudieron haber tenido consecuencias beneficiosas desconocidas hasta ahora.

Otra diferencia política entre Gran Bretaña y la mayor parte de los países europeos era la falta de centralización del poder político. El sistema británico de gobierno dejaba gran parte de la gestión cotidiana de los asuntos en manos de los magistrados locales, la mayoría de los cuales eran residentes respetables para quienes la administración era un pasatiempo. El que este gobierno llevado por aficionados fuera una manera efectiva de prestar servicios gubernamentales es otra cuestión, pero de aquí se deriva la relativa poca importancia de Londres como centro administrativo y cultural cuando se compara con $\mathrm{Ma}$ drid, París o Viena. En Francia, por ejemplo, París atraía tradicionalmente todo el talento de las provincias, por lo que no existían centros locales de estudio y de tecnología como la Manchester Literary and Philosophical Society (Sociedad Literaria y Filosófica de Manchester) o las Universidades de Glasgow y Edimburgo, situadas cerca de centros industriales. Esta fuga de cerebros del campo a la ciudad no hubiera importado, por supuesto, si la industrialización hubiera podido concentrarse cerca de la capital del país. Sin embargo, resulta interesante señalar que no parece que esto sucediera en ninguna parte. Ni Bruselas, ni París, ni Berlín, ni San Petersburgo, ni ninguna de las otras grandes capitales de Europa se convirtieron en centros de la industria moderna. Si bien se desarrolló alguna actividad manufacturera alrededor de las capitales, los principales centros de la industria moderna se hallaban, por lo general, en otros lugares. Así, un Estado muy centralizado, en el que la capital drenaba el campo de sus hombres más ambiciosos y capaces, atraídos por «donde estaba la movida», funcionaba con desventaja si lo comparamos con un Estado descentralizado como Gran Bretaña ${ }^{31}$. Wrigley (1967) ha sostenido prácticamente lo contrario, ascribiendo a Londres un papel fundamental en la creación de las condiciones que condujeron a la Revolución Industrial. El tamaño de Londres, en relación con la población de Inglaterra, y sus enormes necesidades en términos de alimentación, combustible y otros productos parecen apoyar su tesis. Sin embargo, un gran tamaño no es necesariamente una ventaja. Asimismo, se puede considerar que una gran capital impone un coste importante al país. La argumentación de Wrigley parece más adecuada para explicar el desarrollo comercial anterior a 1750 que el desarrollo industrial posterior. En realidad, el predominio demográfico londinense

31 Véase Cardwell (1972, p. 126) para una argumentación similar. Lo que es bastante interesante es que Irlanda, con un gobierno centralizado en Dublín, se ajuste más al modelo de la Europa continental que al de Gran Bretaña. 
declinó un poco durante la Revolución Industrial. Entre 1650 y 1750 la participación de Londres en la población inglesa pasó de alrededor de un 7 por 100 a un 11,8 por 100 , mientras que en 1800 este porcentaje había bajado a un 10,5 por $100^{32}$.

Algunos historiadores han argüido que el gobierno británico estimuló la Revolución Industrial al crear una demanda de productos militares, lo cual condujo a una rápida transformación tecnológica en algunas industrias (McNeill, 1982, pp. 210-212). Es cierto que algunas de estas externalidades se pueden identificar. La técnica del laminado y del pudelado de Cort se terminó de desarrollar mientras que el inventor trabajaba para la Armada. La fresadora de Wilkinson, que perforaba los cilindros con la exactitud que necesitaba la máquina de vapor de Watt, estaba destinada originalmente para perforar cañones. Sin embargo, la mayoría de los estudiosos parecen estar de acuerdo en que estos efectos fueron relativamente pequeños y en que, mirándolo bien, las consecuencias de las guerras que se dieron entre 1756 y 1815 fueron negativas (Trebilcock, 1969, pp. 477-478; Hyde, 1977, pp. 112-116). No es sólo que la evidencia para establecer esta hipótesis no es clara, también nos encontramos ante el dilema de que si los esfuerzos militares crearon importantes externalidades tecnológicas, ¿por qué no se beneficiaron Francia y otros países de Europa continental de ellas de la misma manera que lo hizo Gran Bretaña?

En resumen, la mayor parte de los historiadores económicos estarían de acuerdo en que la política fue un factor positivo que funcionó a favor de Gran Bretaña, aunque la magnitud exacta del efecto, así como su modus operandi, se sigue debatiendo. El tipo de juicio apropiado debe ser el comparativo, y parece difícil no estar de acuerdo con la proposición de que la forma de gobierno de Gran Bretaña creó un entorno más propicio al desarrollo económico que la de otros países. Estaban en vigor algunas leyes mercantilistas opresivas, pero la mayoría se evadieron con éxito. Los británicos pagaban muchos impuestos, pero nunca se permitió que fueran arbitrarios y confiscatorios. $\mathrm{Y}$, lo que es más importante, el derecho de poseer y administrar propiedad era realmente sacrosanto, lo que contrastaba mucho con las confiscaciones y los reclutamientos de la Revolución Francesa y de la era napoleónica. La libertad personal, con algunas excepciones, se aceptaba de forma generalizada en Gran Bretaña. Es cierto que las leyes de asentamiento permanecieron en vigor hasta 1834, pero no eran, de ningún modo, tan restrictivas como las duras disposiciones vigentes en Francia y en Prusia, que exigían que los tra-

32 Las estimaciones de los habitantes de Londres están tomadas de Wrigley (1967, p. 44). Los datos sobre la población inglesa (a excepción Monmouth) son de Wrigley y Schofield (1981). 
bajadores tuvieran cabiers o wanderbücher en los que anotaban sus empleos, y que establecían la necesidad de solicitar pases para viajar por el país. La servidumbre seguía existiendo al este de Elba en 1815. Sólo la catártica medicina revolucionaria administrada al Continente europeo entre 1789 y 1815 por los franceses preparó al resto de Europa para la modernidad. Pero los efectos secundarios inmediatos de esta medicina fueron tan dolorosos que la mayoría de los países tardaron muchos años, e incluso décadas, en recuperarse del tratamiento y en empezar a amenazar el liderazgo británico. A Gran Bretaña no le hizo falta este duro tratamiento de choque, ya que había aprendido sola a adaptar sus instituciones a las necesidades cambiantes por medios más pacíficos, y el Canal de la Mancha la protegía de importaciones políticas no deseadas.

La estabilidad política de Gran Bretaña contrasta mucho con la historia de Francia, con cuatro revoluciones importantes en las ocho décadas posteriores a 1789. Pero ¿fue siempre esta estabilidad una ventaja en el camino de la modernización? El sentido común sugiere que los inversores serían precavidos a la hora de invertir en entornos políticamente inestables. Es probable que la estabilidad política fuera una ventaja y que su ausencia tuviera efectos negativos sobre la industrialización. Sin embargo, ¿qué importancia tuvieron estos efectos? $\mathrm{Y}$ ¿cómo juzgamos la actuación económica de los poderosos regímenes autocráticos de Rusia y de Prusia? Además, Olson (1982) ha insistido en que la estabilidad política es, de hecho, una ventaja a medias dado que permite la cristalización de grupos de presión cuyas actividades son, desde su punto de vista, enemigos jurados del desarrollo económico. Así, pues, no 'está muy claro en qué medida la diferencia en el desarrollo económico se puede atribuir a este hecho ${ }^{33}$. Con todo, no es exagerado decir que en ningún lugar del mundo se percibió que la propiedad estuviera más segura que en Gran Bretaña.

\section{Sociedad y empresariado}

Quizá la hipótesis más controvertida es la de que el éxito milagroso de Inglaterra fue resultado de las características especiales de la sociedad británica, que propiciaron el desarrollo económico. La inventiva, la acumulación

${ }^{33}$ La Revolución Francesa puede haber aumentado la percepción de inseguridad de la propiedad e inhibido la formación de capital. Igualmente, en Irlanda, las luchas continuas entre los propietarios de tierras y los campesinos redujeron su atractivo como emplazamiento del capital industrial (como es el caso de Iilanda del Norte en la actualidad). La primera guerra carlista (1832-39) en España y las guerras miguelinas en Portugal (1828-34) tuvieron efectos similares en la Península Ibérica. 
de capital, la naturaleza sacrosanta de la propieçad privada, la disposición del régimen a alterar el entorno para adaptarlo a las necesidades cambiantes y el interés de los científicos e ingenieros en aplicar la ciencia a la industria se corsideran "endógenos al sistema», es decir, consecuencias de condiciones sociales más profundas. En el centro del escenario, de acuerdo con este punto de vista, se encuentra una figura controvertida, héroe para algunos, mero acompañante para otros: el empresario.

La Nueva Historia Económica se ha sentido incómoda con las explicaciones acerca del éxito y del fracaso económico basadas en la sagacidad empresarial o en el éxito individual. El empresariado, el elemento fundamental en el modelo de desarrollo económico de Schumpeter (1934), parece adecuarse mal a la teoría económica moderna, que supone que los agentes económicos (o por lo menos la mayoría de ellos) intentan prosperar lo más posible. Las oportunidades de realizar un beneficio vendiendo en un mercado recién abierto, utilizando una nueva maquinaria, explotando una nueva veta o prestando dinero a un gobierno solvente no permanecen sin aprovechar por mucho tiempo. Si un hombre de negocios no lo hace, otros tomarán su lugar. Sin embargo, otros historiadores económicos, encabezados por David S. Landes (1969 a), han insistido en la importancia de la oferta de empresariado como un determinante de las experiencias económicas divergentes de la industrialización. Sería precipitado deducir que ha triunfado uno de estos dos enfoques. Con todo, la tradición schumpeteriana, que considera fundamental al empresario, no es realmente incompatible con la teoría neoclásica. El supuesto implícito de algunos cliómetras no es tanto que el empresariado no fue importante como que su oferta era altamente elástica y disponible en todo el mundo al mismo precio. Según este punto de vista, es posible considerar al empresariado de manera similar a como tratamos las materias primas anteriormente: si una economía no tiene una oferta adecuada de ellos se pueden crear o importar.

Las explicaciones convincentes del cambio económico a largo plazo requieren algún elemento causal que sea exógeno, es decir, que no necesite una interpretación económica. Se cree que las diferencias en la calidad del empresario son una explicación débil de las desigualdades económicas entre las naciones, ya que las condiciones económicas determinan esta calidad. Por lo tanto, es necesario descubrir si existieron determinantes no económicos detrás de las diferencias, en cualidades empresariales tales como la disposición a correr riesgos, la competencia, la iniciativa, la perseverancia y elementos similares que se consideran parte de un empresariado con éxito.

Una teoría del empresariado muy conocida y sumamente controvertida es la que vincula de alguna manera a los hombres de negocios con la religión. 
Propuesta originalmente por Weber, la argumentación tiene más éxito al explicar las diferencias entre el cristianismo occidental y el resto del mundo que al aclarar las que se dan en Occidente (White, 1978). Sin embargo, algunos científicos sociales modernos han mostrado un ingenio considerable en su intento de establecer y justificar la relación entre la religión y el desarrollo económico. Así, McClelland (1961) define la necesidad personal de tener éxito (n-Achievement) como el primer motor de desarrollo. Los no conformistas de Inglaterra, debido a su deseo de éxito más elevado, fueron «más responsables del incremento de la actividad empresarial que provocó la Revolución Industrial desde alrededor de 1770 en adelante» (ibid., p. 146). McClelland destaca especialmente a la Iglesia wesleyana, que hacía mucho hincapié en la excelencia personal y en el éxito, y así promovía el tipo de motivación que llevaba a un comportamiento empresarial. No obstante, desafortunadamente para esta tesis, no ha sido posible encontrar demasiados empresarios que pertenecieran a esta Iglesia. Más prometedoras son las definiciones más amplias del no conformismo. Everett Hagen (1962) ha mostrado que los empresarios no conformistas desempeñaron, en realidad, un papel desproporcionado en la Revolución Industrial. Aunque constituían el 7 por 100 de la población total, suponían casi la mitad de los principales innovadores de la industria manufacturera. Hagen rechaza la tesis de Weber de que la relación causal se efectuó a través del dogma y, en su lugar, se centra en un modelo psicológico de comportamiento empresarial. En este modelo, el empresariado se vio ayudado por una reacción de los hijos de padres «aislados» que habían sido rechazados por la sociedad a causa de su disidencia. Aunque la teoría de Hagen no ha conseguido muchos partidarios, es un intento audaz de infundir a este asunto un pensamiento original interdisciplinario, y es una pena que no se hayan realizado más intentos de aplicar la teoría psicológica para una comprensión más profunda de los hombres que llevaron a cabo la Revolución Industrial.

El intento más completo y convincente de dar una explicación social a la Revolución Industrial lo. ha efectuado Perkin (1969). Este autor fecha la creación de un tipo de sociedad más propicio a una Revolución Industrial en la Restauración de 1660 y en los cambios sociales y políticos que la acompañaron ${ }^{34}$. Indica que el principio sobre el que se asentó la sociedad al terminar la guerra civil inglesa fue la relación entre riqueza y posición social. Por posición social se entiende no sólo la influencia política y el control indirecto sobre las vidas de los vecinos, sino también a qué casas se era invitado, a quién se podía elegir para casar a los hijos, qué graduación se podía alcanzar

34 Algunos historiadores sociales sostienen que los cambios se iniciaron mucho antes. Alan MacFarlane (1978, pp. 199-201) fecha explícitamente el comienzo de la «sociedad moderna* inglesa en algún momento anterior a la peste negra. 
(es decir, comprar) en el Ejército, dónde se vivía y cómo se educaba a los hijos. Desde el punto de vista de Perkin, la calidad de vida la determinaba no sólo el «consumo», como lo definen generalmente los economistas, sino la posición relativa del individuo en la jerarquía social. Es una cuestión abierta a debate si esta hipótesis de la relatividad social sigue siendo una buena descripción de la sociedad, aunque se puede defender, como hace Perkin, que es una descripción adecuada de Gran Bretaña en el siglo xviII. Perkin cita un párrafo de la Theory of Moral Sentiments de Adam Smith, que los economistas - -siempre un poco eclécticos en lo que han aprendido del maestro- han pasado por alto a su propia costa:

¿Qué fin tiene todo el esfuerzo y la agitación del mundo... la persecución de riqueza, de poder y de preeminencia? ¿Es para satisfacer las necesidades de la naturaleza? Los salarios de los trabajadores más humildes pueden cubrirlas... ¿Cuál es, entonces, la causa de nuestra aversión a su situación?... ¿Se imaginan los ricos que su estómago es mejor, o que su sueño es más profundo en un palacio que en una choza? A menudo se ha observado lo contrario... Entonces, ¿cuáles son las ventajas de este gran fin de la vida humana que llamamos mejorar nuestra condición?... Es la vanidad, y no la comodidad del placer, lo que nos interesa. Pero la vanidad siempre se basa en nuestra creencia de que somos objetos de atención y de aprobación. El rico se enotgullece de sus riquezas, porque piensa que éstas, naturalmente, dirigen hacia él la atención del mundo... Todo el mundo desea mirarlo... Sus acciones son objeto de atención pública. Pocas palabras puede decir, pocos gestos puede hacer que se ignoren completamente. En una gran reunión él es la persona hacia la que se dirigen todas las miradas... Es esto lo que... da grandeza al objeto de envidia y lo compensa... todo el esfuerzo, toda la ansiedad, todas las mortificaciones que se deben sufrir en su consecución (Smith, 1759, pp. 50-51).

En palabras de Perkin, «al perenne deseo de riqueza; la vieja sociedad [es decir, Gran Bretaña después de 1660] añadió más motivaciones, que dieron significado y propósito a la persecución de riquezas. Comparada con sociedades vecinas más tradicionales, ofrecía tanto un desafío mayor como una mayor recompensa a la empresa con éxito... la persecución de riquezas era la búsqueda de una posición social no sólo para uno mismo, sino para su familia» (Perkin, 1969, p. 85) ${ }^{35}$. La idea de Perkin es importante porque sub-

${ }^{35}$ Perkin anticipa aquí el interesante trabajo de Fred Hirsch (1976), quien, a pesar 
raya un hecho básico, a menudo pasado por alto por los economistas que intentan comprender el comportamiento empresarial. Es, casi siempre, cierto que un individuo racional no dejará de lado una ocasión fácil de ganar dinero. Además, uno pensaría que, si existen divergencias de opinión acerca de la rentabilidad esperada de un proyecto, los optimistas sustituirian a los pesimistas. Si no se aprovechan las oportunidades de obtener ganancias rápidas, éstas desaparecerán pronto. En la Revolución Industrial hubo ocasiones de hacer dinero, pero pocas fueron rápidas y fáciles. La mayoría de las principales figuras empresariales corrieron grandes riesgos, trabajaron mucho y durante muchas horas y pocas veces gozaron de los frutos de sus esfuerzos antes de la vejez, o los disfrutaron indirectamente a través de sus descendientes (Crouzet, 1984, p. 135). El factor empresarial sería más abundante si las recompensas monetarias excedieran los costes de asumir riesgos, de trabajar mucho y de obtener la recompensa al cabo de muchos años. La tesis de Perkin pone de relieve el lado de los beneficios en esta ecuación: en Gran Bretaña, el dinero compró algo más que confort. Esta tesis es perfectamente consistente con la lógica económica y se debe considerar como complementaria de la Nueva Historia Económica.

Con todo, hay que responder a algunas cuestiones empíricas antes de que se pueda aceptar como una explicación del éxito de Gran Bretaña ${ }^{36}$. ¿Era mayor en Gran Bretaña la correlación entre riqueza y posición social que en otros países? Al menos en un caso, Holanda, esto es probablemente falso, lo que indica que tener «el tipo de sociedad apropiada» no es condición suficiente para que se produzca con éxito una Revolución Industrial ${ }^{37}$. Pero ¿qué decir de Francia? En el siglo xvirr se podían comprar los títulos aristocráticos, y gran parte de la nobleza era una noblesse de robe, es decir, de origen burgués. ¿Era mayor en Francia la aversión a los nuevos ricos entre las clases altas que en Gran Bretaña? Si bien esta pregunta no se puede res-

de no estar interesado en Historia, establece una estructura que complementa la de Perkin. Hirsch distingue entre bienes materiales, es decir, las mercancías comunes, y bienes posicionales, de los que hay, por definición, una cantidad constante. Ejemplos de estos últimos son el prestigio social, el poder político y los símbolos que indican la posición social relativa. Los mercados de bienes materiales tienden a estar bien desarrollados, por lo que la riqueza material proporciona un acceso fácil a ellos. Los mercados de bienes posicionales están menos desarrollados. Cuanto más eficientes sean estos mercados, más fácil es adquirir los bienes, gracias a la acumulación de riqueza, o perderlos por carecer de ella. Por lo tanto, los mercados de bienes posicionales relativamente eficientes refuerzan el incentivo a hacerse rico (incrementan la utilidad marginal de la renta) y hacen que merezca la pena todo el esfuerzo y los riesgos del empresariado.

${ }^{36}$ Los intentos posteriores de Perkin para explicar la cronología de la Revolución Industrial en términos del crecimiento de la población y de la demanda han tenido menos éxito. Algunas de estas cuestiones serán tratadas en la segunda parte de este artículo.

${ }^{37}$ Para una explicación económica del fracaso de la industrialización en los Países Bajos, véanse Mọkys (1976) y Griffiths (1979). 
ponder fácilmente, existían a este respecto dos diferencias importantes entre los dos países. En primer lugar, en Francia el dinero podía mejorar la posición social, pero el respetable caballero rural que administraba los asuntos del municipio era una institución totalmente británica. En segundo lugar, en Francia la posición social se compraba con frecuencia. El precio de un título de nobleza reflejaba una exención fiscal, de modo que la venta de títulos no era una vía mediante la cual la Corona se enriquecía. Sin embargo, la nobleza llevaba asociados unos altos niveles de consumo en la tradición de la noblesse oblige. En cambio, en Inglaterra la riqueza estaba correlacionada con la influencia y el respeto, aunque no se tenía necesariamente que gastar aquélla para conseguir éstos.

Además, la lógica de Perkin supone un dinamismo casi dialéctico de la oferta de empresariado. Si los comerciantes y los fabricantes ganaban dinero con el fin de comprar, para ellos o sus descendientes, la buena vida del caballero rural, las filas de la clase empresarial se habrían visto reducidas constantemente. De este modo, la movilidad hacia arriba por motivos de riqueza también conduciría a la larga a la destrucción de la clase empresarial. Tras conseguir su nueva posición social, la nueva élite tendía a cerrar la puerta a otros candidatos. Esta «aristocratización» de las clases comercial e industrial, a la que se ha acusado de la decadencia del liderazgo británico en la era victoriana (Wiener, 1981), parece una extensión lógica de la tesis de Perkin. Al quedar el debate sobre el «fracaso» de la Gran Bretaña victoriana fuera del ámbito de este artículo, no podemos desarrollar en él esta hipótesis.

\section{(Traducción de Angelines Conde Gutiérrez del Alamo.)}

\section{BIBLIOGRAFIA}

As r ron, T. S. (1948): The Industrial Revolution, 1760-1830, Nueva York.

- (1955): An Economic History of England: The 18th Century, Londres (reimpreso en 1972).

- (1968): Iron and Steel in the Industrial Revolution, 4." ed. (publicado originalmente en 1924), Manchester.

Atkinson, A. B., y Stiglitz, J. G. (1969): «A New View of Technological Change», Economic Journal, 79, 3, pp. 573-578.

Berg, M. (1985): The Age of Manufactures, 1700-1820, Londres.

Berrill, K. E. (1960): «International Trade and the Rate of Economic Growth», Economic History Review, XII, 3, pp. 351-359.

Bienefeld, M. A. (1972): Working Hours in Britisb Industry, Trawbridge.

Blanqui, J. A. (1837): Histoire de l'Economie Politique, París.

Blaug, M. (1961): "The Productivity of Capital in the Lancashire Cotton Industry during the Nineteenth Century», Economic History Review, XIII, 3, pp. 358-381. 
Boserup, E. (1981): Population and Technological Change, Chicago.

Bowley, A. L. (1898): "The Statistics of Wages in the United Kingdom. Part. I. Agricultural Wagesm, Journal of the Royal Statistical Society, LXI, Parte IV, pp. 702-722.

Boyer, G. R. (1983): "An Economic Model of the English Poor Law, 1780-1834», Cornell University, Dept. of Labor Economics Working Paper no. 49, Ithaca (Nueva York).

- (1986): «Malthus Was Right After All» (inédito), Cornell University.

BRENNER, R. (1985): Betting on Ideas: Wars, Invention, Inflation, Chicago.

Briavoinne, N. de (1839): De l'industrie en Belgique, causes de décadence et de prosperité sa situation actuelle, 2 vols., Bruselas.

Byt helL, D. (1969): The Handloom Weavers, Cambridge.

- (1978): The Sweated Trades, Nueva York.

Cameron, R. E. (1967): Banking in the Early Stages of Industrialization, Nueva York.

CARDWELL, D. S. L. (1972): Turning Points in Western Technology, Nueva York.

Ch ambers, J. D. (1953): «Enclosure and Labour Supply in the Industrial Revolution», Economic History Review, V, 3, pp. 319-343.

Ch URCH, R. A. (ed.) (1980): The Dynamics of Victorian Business: Problems and Perspectives to the 1870s, Londres.

Cipolla, C. M. (1969): Literacy and Development in the West, Harmondsworth.

Clap ham, J. H. (1926-38): An Economic History of Modern Britain, 3 vols., Cambridge.

Conrs, A. W. (1958): "Changing Attitudes to Labour in the Mid-Eighteenth Century", Economic History Review, pp. 35-51; reimpreso en M. W. Flinn y T. C. Smout (eds.) (1974): Essays in Social History, Londres.

Co HEN, J. S. (1981): «Managers and Machinery: An Analysis of the Rise of Factory Production", Australian Economic Papers, XX, 36, pp. 24-41.

Coleman, D. C. (1983): «Proto-Industrialization: A Concept too Many», Economic History Review, XXXVI, 3, pp. 435-448.

Collier, F. (1964): The Family Economy of the Working Classes in the Cotton Industry, 1784-1833, Manchester.

Collins, B. (1981): «Irish Emigration to Dundee and Paisley During the First Half of the Nineteenth Centurys, en J. M. Goldstrom y L. A. Clarkson (eds.): Irish Population, Economy, and Society. Essays in Honour of K. H. Connell, Oxford, pp. 195-212.

Colnins, M. (1983): «Long-Term Growth of the English Banking Sector and Money Stock, 1844-80m, Economic History Review, XXXVI, 3, pp. 379-395.

Colqu Empire, Londres, 1: ed. de 1814.

CotTrell, P. L. (1980): Industrial Finance, 1830-1914, Londres.

Crapts, N. F. R. (1976): «English Economic Growth in the Eighteenth Century: A ReExamination of Deane and Cole's Estimates», Economic History Review, XXIX, 2, pp. 226-235.

- (1977): «Industrial Revolution in England and France: Some Thoughts on the Question "Why Was England First" ", Economic History Review, XXX, 3, pp. 421-441; reimpreso en Mokyr (1985), pp. 119-131.

- (1978): «Entrepreneurship and a Probabilistic View of the British Industrial Revolution: Reply", Economic History Review, XXXI, 4, pp. 612.614; reimpreso en Mokyr (1985), pp. 135-136.

- (1980): «Income Elasticities of Demand and the Release of Labour by Agriculture During the British Industrial Revolution», Journal of European Economic History, 9, 1, pp. 153-168; publicado con revisiones en Mokyr (1985), pp. 151-163.

- (1981): «The Eighteenth Century: A Survey», en R. C. Floud y D. N. McCloskey (eds.): The Economic History of Britain Since 1700, vol. I, Cambridge, pp. 1-16.

- (1983): «British Economic Growth, 1700-1831: A Review of the Evidence», Economic History Review, XXXVI, 2.

- (1985): British Economic Growth during the Industrial Revolution, Oxford.

- (1986): «British Economic Growth, 1700-1850: Some Difficulties of Interpretation», presentado en el Congreso de la Social Science History Association, St. Louis, 1986; aparecerá en Explorations in Economic History. 
Craig, G. (1980): Germany, 1860-1945, Nueva York.

Crane, C. (1983): «The Industrial Revolution and the Effect on the Market for Child Labor» (inédito), Northwestern University.

Crouzer, F. (1965): "Capital Formation in Great Britain During the Industrial Revolution», en The Proceedings of the Second International Conference of Economic History, La Haya, reimpreso en F. Crouzet (ed.) (1972): Capital Formation in the Industrial Revolution, Londres, pp. 162-222.

- (1967): «England and France in the Eighteenth Century: A Comparative Analysis of Two Economic Growths», en R. M. Hartwell (ed.): The Causes of the Industrial Revolution in England, Londres.

- (1972): «Editors Introduction», en F. Crouzet (ed.): Capital Formation in the Industrial Revolution, Londres, pp. 1-69.

- (1980): «Toward and Export Economy: British Exports During the Industrial Revolution», Explorations in Economic History, XVII, 1, pp. 48-93.

- (1985): The First Industrialists: The Problem of Origins, Cambridge.

Cullen, L. M. (1969): «Irish Economic History: Fact and Myth», en L. M. Cullen (ed.): The Formation of the Irish Economy, Cork, pp. 113-124.

David, P. A. (1975): Technical Choice, Innovation and Economic Growth, Cambridge.

Davis, R. (1979): The Industrial Revolution and British Overseas Trade, Leicester.

Deane, P., y Cole, W. A. (1969): British Economic Growth, 1688-1959, 2." ed., Cambridge; 1 : $^{*}$ ed. de 1962.

Derry, T. K., y Williams, T. I. (1960): A Short History of Technology, Oxford.

Engerman, S. L. (1972): "The Slave Trade and British Capital Formation in the Eighteenth Century», Business History Review, XLVI, 4, pp. 430-443.

Eversley, D. E. C. (1967): «The Home Market and Economic Growth in England, 17501780 , en E. L. Jones y G. E. Mingay (eds.): Land, Labour and Population in the Industrial Revolution, Cambridge, pp. 206-259.

Falkus, M. E. (1982): «The Early Development of the British Gas Industry, 1790-1815», Economic History Review, XXXV, 2, pp. 217-234.

Feinstein, C. H. (1978): "Capital Formation in Great Britain», en P. Mathias y M. M. Postan (eds.): Cambridge Econ. History of Europe, vol. 7, parte 1.2, Cambridge, pp. 28-96.

- (1981): «Capital Accumulation and the Industrial Revolution», en R. C. Floud y D. N. McCloskey (eds.): The Economic History of Britain since 1700, Cambridge, pp. $128-142$.

FIELD, A. J. (1979): «Occupational Structure, Dissent, and Education Commitment: Lancashire, 1841», en P. Uselding (ed.): Research in Economic History, vol. 4, pp. 235-288.

Findlay, R. (1982): «Trade and Growth in the Industrial Revolution», en C. P. Kindleberger y G. di Tella (eds.): Economics in the Long View. Essays in Honour of W. W. Rostow, Nueva York, vol. I, pp. 178-188.

FLINN, M. W. (1966): Origins of the Industrial Revolution, Londres.

- (1981): The European Demographic System, 1500-1820, Baltimore.

Floud, R. (1986): «New Dimensions of the Industrial Revolution», presentado en el Congreso de la Social Science History Assoication, St. Louis, 1986.

Fogel, R. W. (1983a): «Scientific History and Traditional History», en R. W. Fogel y G. R. Elton: Which Road to the Past?, New Haven, pp. 7-70.

- (1983 b): "Secular Changes in American and British Stature and Nutrition», Journal of Interdisciplinary History, XIV, 2, pp. 445-482.

- (1984): «Growth as a Measure of the Economic Well-Being of Populations in the Eighteenth and Nineteenth Centuries» (inédito), University of Chicago.

Fores, M. (1981): «The Myth of a British Industrial Revolution», History, LXVI, 217, pp. 181-198.

Freudenberger, H. (1966): «The Mercantilist Proto-Factories», Business History Review, $\mathrm{XL}$, pp. 167-189.

- (1974): «Das Arbeitjahr», en I. Bog et al. (eds.): Wirtschaftliche und Soziale Strukturen im saekularen Wandel, Hanover, pp. 307-320. 
Freudenberger, H., y Cummins, G. (1976): Health, Work and Leisure Before the Industrial Revolution», Explorations in Economic History, XIII, 1, pp. 1-12.

GAYeR, A.; Rostow, W. W., y SCH WARTZ, A. J. (1953): The Growth and Fluctuations of the British Economy, 1790-1850, Oxford.

Gersch enkron, A. (1962): Economic Backwardness in Historical Perspective: A Book of Essays, Cambridge (Mass.).

Goldstone, J. (1981): «The Origins of the English Revolution: a Demographic Approach" (tesis doctoral inédita), Harvard University.

Good, D. F. (1973): «Backwardness, and the Role of Banking in Nineteenth-Century European Industrializationn, Journal of Economic History, XXXIII, 4, pp. 845-850.

Great Britain (1818): «Report from the Select Committee Appointed to Consider the Effect of the Laws Which Regulate or Restrain the Interest of Money».

GRIFFITHS, R. (1979): Industrial Retardation in the Netberlands 1830-1850, La Haya.

HabakKuK, H. J. (1963): «Population Problems and European Economic Development in the Late Eighteenth and Nineteenth Centuries», American Economic Review, LIII, 2, pp. $607-618$.

Habakkuk, H. J., y Deane, P. M. (1963): «The Take-off in Britain», en W. W. Rostow (ed.): The Economics of Take-off into Sustained Growth, Londres.

Hagen, E. E. (1962): On the Theory of Social Change: How Economic Growth Begins, Homewood (Illinois).

HARLEY, C. K. (1982): «British Industrialization Before 1841: Evidence of Slower Growth During the Industrial Revolution», Journal of Economic History, XLII, 2, pp. 267-290.

HARTwell, R. M. (1967): The Causes of the Industrial Revolution in England, Londres. - (1971): The Industrial Revolution and Economic Growth, Londres.

Hartwell, R. M., y Engerman, S. (1975): «Models of Immiseration: the Theoretical Basis of Pessimism», en A. J. Taylor (ed.): The Standard of Living in Britain in the Industrial Revolution, Londres, pp. 189-213.

Hatton, T. J.; Lyons, J. S., y SAtchell, S. E. (1983): «Eighteenth Century British Trade: Homespun or Empire Made?», Explorations in Economic History, XX, 2, pp. 163-182.

Heaton, H. (1937): «Financing the Industrial Revolution», Bulletin of the Business Historical Society, XI, 1; reproducido en F. Crouzet (ed.) (1972): Capital Formation in the Industrial Revolution, Londres, pp. 84-93.

- (1948): Economic History of Europe, Nueva York.

Henderson, W. O. (1954): Britain and Industrial Europe, 1750-1870, Londres; 3." ed., 1972.

Hrcks, J. R. (1946): Value and Capital, Londres.

- (1969): A Theory of Economic History, Londres.

HIRSC H, F. (1976): Social Limits to Growth, Cambridge (Mass.).

HoffmanN, W. G. (1955): British Industry 1700-1950, Oxford.

Honeyman, K. (1983): Origins of Enterprise: Business Leadersbip in the Industrial Revolution, Nueva York.

Hopkins, E. (1982): «Working Hours and Conditions During the Industrial Revolution: A Re-Appraisalw, Economic History Review, XXXV, 1, pp. 52-66.

Houston, R. A. (1982 a): «The Development of Literacy: Northern England, 1640-1750», Economic History Review, XXXV, 2, pp. 199-216.

- $(1982 b)$ : «The Literacy Myth: Illiteracy in Scotland 1630-1760», Past and Present, 96, pp. 81-102.

Hueckel, G. (1973): «War and the British Economy, 1793-1815: A General Equilibrium Analysisw, Explorations in Economic History, X, pp. 365-396.

Hug HeS, J. R. T. (1969): «Henry Mayhew's London», Jouirnal of Economic History, XXIX, 3, pp. 526-536.

- (1970): Industrialization and Economic Historv. Nueva York. 
Huzel, J. P. (1969): «Malthus, the Poor Law, and Population in Early Nineteenth Century England", Economic History Review, XXII, 3, pp. 430-452.

- (1980): «The Demographic Impact of the Old Poor Law: More Reflections on Malthus», Economic History Review, XXXIII, 3, pp. 367-381.

Hyde, C. K. (1977): Technological Change and the Britisb Iron Industry, 1700-1870, Princeton (N. J.).

Jeremy, D. J. (1977): «Damming the Flood: British Government Efforts to Check the Outflow of Technicians and Machinery, 1780-1843», Business History Review, LI, 1, pp. 1-34.

JONES, E. L. (1968): «Agricultural Origins of Industry», Past and Present, XL, pp. 58-71.

- (1974): Agriculture and the Industrial Revolution, Nueva York.

- (1981): The European Miracle, Cambridge.

Kerridge, E. (1969): «The Agricultural Revolution Reconsidered", Agricultural History, XLIII, 4, pp. 463.475.

Kravis, I. B. (1970): "Trade as a Handmaiden of Growth: Similarities between the Nineteenth and Twentieth Centuriesm, Economic Journal, LXXX, 320, pp. 850-872.

KRIEDTE, P. (1981): «Proto-Industrialization between Industrialization and de-Industrialization», en P. Kriedte, H. Medick y J. Schlumbohm: Industrialization Before Industrialization, Cambridge, pp. 135-160.

Kuznets, S. (1966): Modern Economic Growtb: Rate, Structure and Spread, Cambridge (Mass.).

LANDEs, D. (1965): «Factor Costs and Demand: Determinants of Economic Growth», Business History, VII, 1, pp. 15-33.

- (1969): The Unbound Prometheus, Cambridge.

- (1986): «What Do Bosses Really Do», Journal of Economic History, XLVI, 3, pp. $585-624$.

LANGER, W. L. (1969): Political and Social Upbeaval, 1832-1852, Nueva York.

Lindert, P. H., y Williamson, J. G. (1982): «Revising England's Social Tables, 1688 1812», Explorations in Economic History, XIX, 4, pp. 385-408.

- (1983a): «English Workers' Living Standards During the Industrial Revolution: A New Look», Economic History Review, XXXVI, 1, pp. 1.25; reproducido en Mokyr (1985), pp. 177-205.

- $(1983 b)$ : «Reinterpreting Britain's Social Tables, 1688-1913», Explorations in Economic History, XX, 1.

Lyons, J. (1979): «Family Response to Economic Decline: English Cotton Handloom Weavers in the Nineteenth Century» (inédito), Washington, D. C.

McClelland, D. C. (1961): The Acbieving Society, Princeton.

McCloskey, D. N. (1973): «New Perspectives on the Old Poor Law», Explorations in Economic History, X, 4, pp. 419-436.

- (1981): «The Industrial Revolution 1780-1860: A Survey», en R. Floud y D. N. McCloskey (eds.): The Economic History of Britain since 1700, 2 vols., I, pp. 103-127; reproducido con revisiones en Mokyr (1985), pp. 53-74.

MacFardane, A. (1978): The Origins of English Individualism, Nueva York.

MCKendrick, N. (1974): «Home Demand and Economic Growth: a New View of the Role of Women and Children in the Industrial Revolution», en N. McKendrick (ed.): Historical Perspectives. Studies in English Thought and Society in Honour of J. H. Plumb, Londres, pp. 152-210.

McNeIll, W. H. (1982): The Pursuit of Power, Chicago.

Mantoux, P. (1961): The Industrial Revolution in the Eighteenth Century, Nueva York y Evanston; 1." ed. inglesa, 1928; 1." ed. francesa, 1905.

Marglin, S. A. (1974-75): «What Do Bosses Do?», Review of Radical Political Economy, VI, 2 (1974), y VII, 1 (1975).

MARRINER, S. (1980): «English Bankruptcy Records and Statistics before 1850», Economic History Review, XXXIII, 3, pp. 351-366.

Mason, S. E. (1962): $A$ History of the Sciences, Nueva York. 
Mathias, P. (1969): The First Industrial Nation: An Economic History of Britain, 1700-1914, Cambridge.

- (1972): "Who Unbound Prometheus? Science and Technical Change, 1600-1800", en A. E. Musson (ed.): Science, Tecbnology, and Economic Growth, Londres.

MAYs HAR, J. (1983.a): «On Divergence of Opinion and Imperfections in Capital Markets", American Economic Review, LXXIII, 1, pp. 114-128.

- $(1983 \mathrm{~b})$ : «Financial Constraints on Investment by the Firm», Dept. of Finance, KGSM, Northwestern University (inédito).

Medick, H. (1981): «The Proto-Industrial Family Economy», en P. Kriedte, H. Medick y J. Schlumbohm: Industrialization Before Industrialization, Cambridge.

Millward, R. (1981): «The Emergence of Wage Labor in Early Modern England», Explorations in Economic History, XVIII, 1, pp. 21-39.

Minc Hinton, W. E. (ed.) (1969): The Growth of English Overseas Trade, Londres.

Mitc H, D. (1982): «The Spread of Literacy in Nineteenth Century England" (tesis doctoral no publicada), University of Chicago.

Mitc h elL, B. R., y Deane, P. (1962): Abstract of British Historical Statistics, Cambridge.

Moxyr, J. (1975): "Capital, Labour and the Delay of the Industrial Revolution in the Netherlands", Economic History Yearbook (Amsterdam), XXXVIII, pp. 280-299.

- (1976): «Growing-Up and the Industrial Revolution in Europe», Explorations in Economic History, XIII, 4, pp. 371-396.

- (1977): «Demand vs. Supply in the Industrial Revolution», Journal of Economic History, XXXVII, 4, pp. 981-1008; reproducido en Mokyr (1985), pp. 97-118.

- (1980): «Industrialization and Poverty in Ireland and the Netherlands: Some Notes Toward a Comparative Case Study», Journal of Interdisciplinary History, $\mathrm{X}, 3$, pp. $429-459$.

- (1982): "Prosperous Interlude», Economic Development and Cultural Change, XXX, 4, pp. 863-869.

- (1983): Why Ireland Starved, Londres.

- (1984): «Consumption and the Standard of Living: Is There Still Life in the Pessimist Case» (inédito), Evanston (II.).

- (ed.) (1985): The Economics of the Industrial Revolution, Londres.

- (1986): «Has the Industrial Revolution been Crowded-Out?», presentado al Congreso de la Social Science History Association, St. Louis, octubre 1986; aparecerá en Explorations in Economic History.

MoxyR, J., y SAvin, N. E. (1976): «Stagflation in Historical Perspective: the Napoleonic Wars Revisited», en P. Uselding (ed.): Research in Economic History, vol. 1, pp. 198-259.

Musson, A. E. (ed.) (1972): Science, Technology and Economic Growth, Londres.

Musson, A. E., y Robinson, E. (1969): Science and Technology in the Industrial Revolution, Manchester.

Nardinelli, C. (1980): «Child Labor and the Factory Acts», Journal of Economic History, XL, 4, pp. 739-755.

NoRT H, D. C. (1981): Structure and Change in Economic History, Nueva York.

O'Brien, P. K. (1982): «European Economic Development: The Contribution of the Periphery», Economic History Review, XXXV, 1, pp. 1-18.

O'BRIEN, P. K., y Engerman, S. L. (1981): «Changes in Income and its Distribution», en R. Floud y D. N. McCloskey (eds.): The Economic History of Britain Since 1700, vol. I, pp. 164-181.

Olson, M., Jr. (1982): The Rise and Decline of Nations, New Haven.

PARKER, W. N. (1972): «Technology Resources and Economic Change in the West», en A. J. Youngson (ed.): Economic Development in the Long Run, Nueva York.

- (1979): "Industry», en P. Burke (ed.): The New Cambridge Modern History, vol. XIII, Cambridge.

PAYNe, P. L. (1974): British Entrepreneurship in the Nineteenth Century, Londres.

PERkIN, H. J. (1969): The Origins of Modern English Society, 1780-1880, Londres.

Polanyi, K. (1944): The Great Transformation, Boston. 
Pollarn, S. (1964): «Fixed Capital in the Industrial Revolution», Journal of Economic History, XXIV, 3.

- (1965): The Genesis of Modern Management, Londres; Ed. Penguin, 1968.

- (1973): «Industrialization and the European Economy», Economic History Review, XXVI, 4, pp. 636-648; reproducido y revisado en Mokyr (1985), pp. 165-176.

- (1978): «Labour in Great Britain», en Mathias y Postan (eds.): The Cambridge Economic History of Europe, vol. 6, Cambridge.

- (1981): Peaceful Conquest: the Industrialization of Europe 1760-1970, Oxford.

Postan, M. M. (1935): «Recent Trends in the Accumulation of Capital», Economic History Review, VI, 1.

Presnell, L. S. (1956): Country Banking in the Industrial Revolution, Oxford.

Ranis, G., y FeI, J. C. H. (1969): «Economic Development in Historical Perspective», American Economic Review, LIX, 2, pp. 386-400.

REDFoRD, A. (1964): Labour Migration in England 1800-1850, Manchester.

REID, D. A. (1976): «The Decline of Saint Monday, 1766-1876», Past and Present, 71, pp. 76-101.

Rosenberg, N. (1963): «Technological Change in the Machine Tool Industry 1840-1910", Journal of Economic History, XXXIII, 4, pp. 414-443.

- (1967): «Anglo-American Wage Differences in the 1820s», Journal of Economic History, XXVII, 2, pp. 221-229.

- (1969): \&The Direction of Technological Change: Inducement Mechanisms and Focusing Devices», Economic Development and Cultural Cbange, XVIII, 1, Parte 1.", pp. 1-24.

- (1976): Perspectives in Tecbnology, Cambridge.

Rostow, W. W. (1960): The Stages of Economic Growth, Cambridge.

- (1978): "No Random Walk: A Comment on "Why Was England First"», Economic History Review, XXXI, 4, pp. 610-611; reproducido en Mokyr (1985), pp. 132-134.

Rule, J. (1983): The Experience of Labour in Eighteenth-Century English Industry, Nueva York.

SandBerg, L. G. (1979): "The Case of the Impoverished Sophisticate: Human Capital and Swedish Economic Growth before World War Im, Journal of Economic History, XXXIX, 1, pp. 225.242.

SANDERSON, M. (1972): «Literacy and Social Mobility in the Industrial Revolution in England», Past and Present, LVI, 56, pp. 75-104.

SAul, S. B. (1970): Technological Change: The United States and Britain in the Nineteenth Century, Londres.

ScH OFIELD, R. S. (1973): "Dimensions of Illiteracy, 1750-1850", Explorations in Economic History, $X, 4$, pp. 437-451.

SCH UMPETER, J. A. (1934): The Theory of Economic Development, Cambridge (Mass.).

- (1939): Business Cycles, Nueva York.

Scitovsky, T. (1971): Welfare and Competition, Homewood (II.).

SMELSER, N. J. (1959): Social Change in the Industrial Revolution, Chicago.

Smit H, A. (1756): Theory of Moral Sentiments, Londres.

- (1776): An Inquiry into the Nature and Causes of the Wealtb of Nations, Londres.

Smout, T. C. (1978): «Famine and Famine-relief in Scotland», en L. M. Cullen y T. C. Smout (eds.): Comparative Aspects of Scottish and Irish Economic History 1600-1900, Edimburgo, pp. 21-31.

Solar, P. (1983): «Poor Relief and Economic Development in Britain and Ireland until the middle Nineteenth Century" (inédito).

Solow, R. M., y Temin, P. (1978): «The Inputs for Growth», en P. Mathias y M. M. Pos$\tan$ (eds.), I, pp. 1-27; reproducido en Mokyr (1985), pp. 75-96.

Solrow, L. (1968): «Long Run Changes in British Income Inequality», Economic History Review, XXI, 1, pp. 17-29.

STyLes, P. (1963): *The Evolution of the Law of Settlement», University of Birmingham Historical Journal, IX, 1, pp. 33-63. 
Szostak, R. (1985): «The Role of Transportation in the Industrial Revolution: A Comparison of Eighteenth Century England and France» (tesis doctoral inédita), Northwestern University.

TAYLOR, A. J. (ed.) (1975): The Standard of Living in Britain in the Industrial Revolution, Londres.

TAylor, J. S. (1969): «The Mythology of the Old Poor Law», Journal of Economic History, XXIX, 2, pp. 292-297.

Tномаs, В. (1980): «Towards an Energy Interpretation of the Industrial Revolution», Atlantic Economic Journal, VIII, 1, pp. 1-15.

- (1982): «Food Supply in the United Kingdom During the Industrial Revolution», Agricultural History, LXVI, 1, pp. 328-342; reproducido en Mokyr (1985), pp. 137-150.

Thомas, R. P., y McCloskey, D. N. (1981): "Overseas trade and Empire 1700-1860», en R. C. Floud y D. N. McCloskey (eds.): The Economic History of Britain Since 1700, vol. I, pp. $87-102$.

Tном оSoN, E. P. (1967): «Time, Work-Discipline and Industrial Capitalism», Past and Present, XXXVIII, pp. 56-97.

TOYNBEE, A. (1884): Lectures on the Industrial Revolution, T. S. Ashton, ed. 1969, Nueva York.

Trebilcock, C. (1969): "Spin-off" in British Economic History: Armaments and Industry, 1760-1914», Economic History Review, XXII, 3, pp. 474-490.

Von Tunzelmann, G. N. (1978): Steam Power and British Industrialization to 1860, Oxford.

- (1981): «Technical Progress during the Industrial Revolution", en R. C. Floud y D. N. McCloskey (eds.): The Economic History of Britain Since 1700, Cambridge, vol. I, pp. 143-163.

- (1982): "The Standard of Living, Investment, and Economic Growth in England and Wales, 1760-1850m, en L. Jörberg y N. Rosenberg (eds.): Tecbnical Change, Employment and Investment, Budapest, pp. 209-224; publicado con revisiones como "The Standard of Living Debate and Optimal Economic Growth", en Mokyr (1985), pp. 207.226.

WEST, E. G. (1978): «Literacy and the Industrial Revolution», Economic History Review, XXXI, 3, pp. 369-383; reproducido en Mokyr (1985), pp. 227-240.

WIENER, M. J. (1981): English Culture and the Decline of the Industrial Spirit, 1850 . 1980, Cambridge.

WhITE, L. (1978): Medieval Religion and Technology, Berkeley.

WILliams, E. (1944): Capitalism and Slavery, Chapel Hill (North Carolina).

Williams, J. E. (1966): «The British Standard of Living, 1750-1850», Economic History Review, XIX, 3, pp. 581.589.

Williamson, J. G. (1980): «Earnings Inequality in Nineteenth-Century Britain», Journal of Economic History, XL, 3, pp. 457-476.

- (1981): «Urban Disamenities, Dark Satanic Mills, and the British Standard of Living Debate», Journal of Economic History, XLI, 1, pp. 75-84.

- (1982): "Was the Industrial Revolution Worth it? Disamenities and Death in Nineteenth Century British Towns», Explorations in Economic History, XIX, 3, pp. 221-245.

- (1984): «Why Was British Growth so Slow during the Industrial Revolution», Journal of Economic History, XLIV, 3, pp. 687-712.

- (1985): Did British Capitalism Breed Inequality?, Boston.

- (1986): «Debating the British Industrial Revolution», presentado al Congreso de la Social Science History Association, St. Louis, octubre 1986; se publicará en Explorations in Economic History.

WrIGLEY, E. A. (1962): «The Supply of Raw Materials in the Industrial Revolution», Economic History Review, XV, 1, pp. 1.16.

- (1967): «A Simple Model of London's Importance in Changing English Society and Economy 1650-1750m, Past and Present, XXXVII, 37, pp. 44-70.

Wrigley, E. A., y SCHOfIEld, R. (1981): The Population History of England, 1541 1871: A Reconstruction, Cambridge. 